Check for updates

Cite this: J. Mater. Chem. A, 2018, 6 , 12598

Received 27th March 2018 Accepted 8th June 2018

DOI: $10.1039 / c 8 t a 02821 d$

rsc.li/materials-a

\section{Novel multifunctional polymethylsilsesquioxane- silk fibroin aerogel hybrids for environmental and thermal insulation applications $\uparrow$}

\begin{abstract}
Hajar Maleki, iD * Lawrence Whitmore and Nicola Hüsing iD
The development of aerogels with improved mechanical properties, to expand their utility in highperformance applications, is still a big challenge. Besides fossil-fuel based polymers that have been extensively utilized as platforms to enhance the mechanical strength of silsesquioxane and silica-based aerogels, using green biopolymers from various sustainable renewable resources are currently drawing significant attention. In this work, we process silk fibroin (SF) proteins, extracted from silkworm cocoons, with organically substituted alkoxysilanes in an entirely aqueous based solution via a successive sol-gel approach, and show for the first time that it is possible to produce homogeneous interpenetrated (IPN) polymethylsilsesquioxane (PMSQ)-SF hybrid aerogel monoliths with significantly improved mechanical properties. Emphasis is given to an improvement of the molecular interaction of the two components (SF biopolymer and PMSQ) using a silane coupling agent and to the design of pore structure. We succeeded in developing a novel class of compressible, light-weight, and hierarchically organized mesomacroporous PMSQ-SF IPN hybrid aerogels by carefully controlling the sol-gel parameters at a molecular level. Typically, these aerogels have a compressive strength $\left(\delta_{\max }\right)$ of up to $14 \mathrm{MPa}$, together with high flexibility in both compression and bending, compressibility up to $80 \%$ strain with very low bulk density $\left(\rho_{\mathrm{b}}\right)$ of $0.08-0.23 \mathrm{~g} \mathrm{~cm}^{-3}$. By considering these promising properties, the superhydrophobic/ oleophilic PMSQ-SF aerogel hybrids exhibited a high competency for selective absorption of a variety of organic pollutants (absorption capacities $\sim 500-2600 \mathrm{~g} \mathrm{~g}^{-1} \%$ ) from water and acted as a highperformance filter for continuous water/oil separation. Moreover, they have demonstrated impressive thermal insulation performance $\left(\lambda=0.032-0.044 \mathrm{~W} \mathrm{~m}^{-1} \mathrm{~K}^{-1}\right)$ with excellent fire retardancy and selfextinguishing capabilities. Therefore, the PMSQ-SF aerogel hybrids would be a new class of open porous material and are expected to further extend the practical applications of this class of porous compounds.
\end{abstract}

\section{Introduction}

Silsesquioxane and other aerogels $\mathbf{s}^{\mathbf{1 , 2}}$ are promising candidates for a wide range of applications, including thermal insulation in construction and space industries, ${ }^{3-5}$ catalysis and photocatalysis supports, ${ }^{6}$ environmental cleaning, ${ }^{7-9}$ and pharmaceutical and biomedical applications ${ }^{\mathbf{1 0 , 1 1}}$ due to their outstanding physical properties, which include very low density, high porosity and high specific surface area., ${ }^{\mathbf{1 2 , 1 2 - 1 5}}$ However, besides these extraordinary properties, traditional silica, and other oxide aerogels are typically very fragile. ${ }^{\mathbf{1 6}}$ This fragility and brittleness is the most important challenge with respect to any practical application. Compared to silica aerogels, polymethylsilsesquioxane (PMSQ, $\mathrm{CH}_{3} \mathrm{SiO}_{1.5}$ ) aerogels, which are derived from the trifunctional

Chemistry and Physics of Materials, Paris-Lodron University Salzburg, Jakob-Haringer-Strasse 2a, 5020, Salzburg, Austria. E-mail: hajar.maleki@sbg.ac.at $\dagger$ Electronic supplementary information (ESI) available: Additional data belong to $[\mathrm{Si}]_{17.5}$, SEM micrographs, FT-IR, $\mathrm{N}_{2}$ adsorption-desorption isotherms, TGA-DTA analysis and so on. See DOI: 10.1039/c8ta02821d methyltrimethoxysilane (MTMS), show a much better compressive mechanical behaviour due to the presence of macropores and $\mathrm{Si}-\mathrm{CH}_{3}$ moieties in the microstructural network. ${ }^{17,18}$ In 2007, Kanamori et al. $^{\mathbf{1 9}}$ extended this approach and developed PMSQ aerogels showing high mechanical durability against compression in combination with high transparency due to the suppression of phase separation during the sol-gel reaction. The same group developed hybrid aerogels from an MTMS-dimethydimethoxysilane (DMDMS) co-precursor system and obtained marshmallow-like white gels with an excellent bending flexibility. ${ }^{20,21}$ In addition to these studies, various other approaches have been developed to overcome the inferior mechanical properties of both silica and PMSQ aerogels without compromising the other physical properties. ${ }^{4,16}$ Besides the pioneering work of Leventis and coworkers, ${ }^{22,23}$ who interlinked silica aerogel networks covalently with polyureas, polyurethanes, epoxies, and polystyrene, other approaches based on the incorporation of discrete nano- or micro-scale secondary phases, such as carbon nanofibers, ceramic, glass or polymer nanoparticles and fibres, have been developed. ${ }^{24-27}$ 
Dispersion of fibrous components derived from biomaterials, such as cellulose nanofibers from bacteria ${ }^{28}$ or plants, ${ }^{29,30}$ pectin, ${ }^{31}$ as well as chitosan, ${ }^{32,33}$ in which the fibre acts as a continuous template or scaffold within the network skeleton in order to mechanically support the delicate structure of silica aerogels, was also reported and nicely summarized in a very recent all-embracing review. ${ }^{34}$ Mixing of these bio-derived fibres with silica is typically performed via in situ sol-gel processing in the presence of an organosilane coupling agent or through soaking the pre-formed silica gel in the biopolymer solution. This is possible since the sol-gel chemistry of silica is very well investigated, and polarities (in the sol, but also of the silica surface) can easily be adapted to match the biological species. Only very recently has this been extended to PMSQ gels. ${ }^{35}$ Biocomposite aerogels of PMSQ-cellulose nanofibers were developed with a good flexibility against bending but a better compressive strength than the previously described marshmallow-like gels. ${ }^{35}$ The concept of hybridization of PMSQ with biopolymers from renewable and sustainable bioresources, such as polysaccharides or proteins, to improve compressive and bending flexibility of PMSQ is also advantageous with respect to their carbon footprint. However, a major challenge is the inherent incompatibility of the very hydrophobic PMSQ network ${ }^{36}$ and the hydrophilic biopolymer, as is found for example in silk fibroin.

Silk fibroin (SF) is a highly abundant fibrous protein-based polymer which is isolated from the Bombyx mori silkworm cocoon. ${ }^{37}$ This biopolymer is fascinating as it offers a high abundance in nature with low cost, biocompatibility and biodegradability, easy surface modification, and versatile processing to various resilient materials such as sponges, microspheres, fibers, hydrogels and so on. ${ }^{37}$ Also, the mechanical strength and toughness of silk fibres are superior to the best synthetic materials such as Kevlar ${ }^{38}$ or common biopolymers such as collagen and poly-L-lactic acid (PLA). However, except for a very recent report of the groups of Mallepally et al. ${ }^{39}$ who developed an SF-based aerogel through a $\mathrm{CO}_{2}$ assisted gelation technique, and Omenetto et al. ${ }^{\mathbf{4 0}}$ who investigated biopolymerbased hierarchical constructs, the formation of SF aerogels by solution processes has not been reported..$^{34}$

In this work, we address the problem of simultaneously processing an extracted aqueous $\mathrm{SF}$ and methyltrimethoxysilane, $\mathrm{CH}_{3} \mathrm{Si}\left(\mathrm{OCH}_{3}\right)_{3}$, the silsesquioxane gel precursor, to structurally design highly porous, hybrid aerogel networks with a homogeneous distribution of both components and extraordinary physical and mechanical properties inherited from the synergism of both materials. Special emphasis is given to the molecular interaction of the two components, $\mathrm{SF}$ and $\mathrm{CH}_{3} \mathrm{SiO}_{1.5}$, using a novel coupling agent, 5-(trimethoxysilyl)pentanoic acid (TMSPM) and a compatibilizing surfactant, to deliberately tailor the pore structure and hence the resulting mechanical properties. To be clear, the production procedure of PMSQ-SF aerogel hybrids is shown in Scheme 1. Several specific challenges are addressed: (1) formation of a homogeneous gel from the very hydrophobic PMSQ and the highly hydrophilic SF gel network; (2) PMSQ network formation is very sensitive regarding the solgel parameters, for example the addition of a coupling agent will readily change the network build-up and subsequently the structural properties, such as macroporosity and the bulk mechanical strength; (3) one-pot sol-gel chemistry requires careful control of the kinetics of the gelation processes of the two different components (SF and PMSQ); and (4) only a thorough structural investigation will give detailed information about the homogeneity of the final hybrid gel network and deeper insights into synthesis-structure-property relationships.

In brief, a combination of superhydrophobic PMSQ aerogel with SF biopolymer offers a straightforward approach to providing a 3D open cellular hybrid structure with tunable surface wettability and mechanical properties for versatile applications.

\section{Experimental methods}

\subsection{Materials}

B. mori silkworm cocoons were purchased from Wild Fibres, UK. Methyltrimethoxysilane (98\% purity, MTMS), hexadecyltrimethylammonium bromide (98\% purity, CTAB), methanol (99.8\%, $\mathrm{MeOH})$, trimethoxysilane (95\% purity), 4-pentenoic acid, ( $\geq 98 \%$ purity), anhydrous lithium bromide (99.99\% purity, $\mathrm{LiBr})$, ammonium hydroxide $\left(28-30 \%, \mathrm{NH}_{4} \mathrm{OH}\right)$, sodium carbonate $\left(\mathrm{Na}_{2} \mathrm{CO}_{3}\right)$, methylene blue (dye content $>82 \%$, $\mathrm{MB}$ ) were obtained from Sigma Aldrich. Acetone, dimethylformamide (DMF), toluene, pump oil were purchased from VWR International. Slide-A-Lyzer ${ }^{\mathrm{TM}} \mathrm{G} 2$ dialysis cassettes, $3.5 \mathrm{~K}$ MWCO, 3-5 mL) were purchased from Thermo Fisher Scientific Inc. All chemicals were used without further purification.

\subsection{Silk fibroin extraction}

SF aqueous solution was extracted from silkworm cocoons through a slightly modified standard procedure reported by Kaplan et al. ${ }^{37}$ First, silk cocoons ( $5 \mathrm{~g}$ ) were cut into dime-sized pieces and boiled for $30 \mathrm{~min}$ in $2 \mathrm{~L}$ of aqueous $\mathrm{Na}_{2} \mathrm{CO}_{3}(0.02 \mathrm{M})$, then the fibers were thoroughly rinsed with ultrapure water and dried overnight. The dry silk fibers were dissolved in aq. $\mathrm{LiBr}$ (12-15 M) solution at $60{ }^{\circ} \mathrm{C}$ for $4 \mathrm{~h}$ and then dialyzed against ultra-pure water for $48 \mathrm{~h}$. The dialyzed SF solution was centrifuged at $9000 \mathrm{rpm}$ twice and stored at $4{ }^{\circ} \mathrm{C}$ for later use.

\subsection{Synthesis of 5-(trimethoxysilyl)pentanoic acid (TMSPA)}

Synthesis of TMSPA has been previously reported by our group. ${ }^{41}$ Trimethoxysilane $(0.05 \mathrm{~mol})$ was added dropwise to a suspension of 4-pentenoic acid (0.05 mol) and platinum(Iv) oxide $(0.05 \mathrm{mmol})$ at $0{ }^{\circ} \mathrm{C}$ in a dry oxygen-free argon atmosphere. After stirring the mixture for $6 \mathrm{~h}$ at $0{ }^{\circ} \mathrm{C}$ and $12 \mathrm{~h}$ at room temperature and filtration over a polytetrafluoroethylene syringe filter, the product was obtained as a light-brown liquid. The colour results from colloidal $\mathrm{Pt}(0)$ particles, which can be removed by the addition of charcoal and dunning filtration.

\subsection{Synthesis of PMSQ-SF composites}

Two different series of PMSQ-SF aerogel hybrids as $[\mathrm{Si}]_{3.5}$ and $[\mathrm{Si}]_{17.5}$, with total silicon molar contents [Si] of 3.5 and $17.5 \mathrm{mmol}$, respectively, were prepared. Additionally, for both 


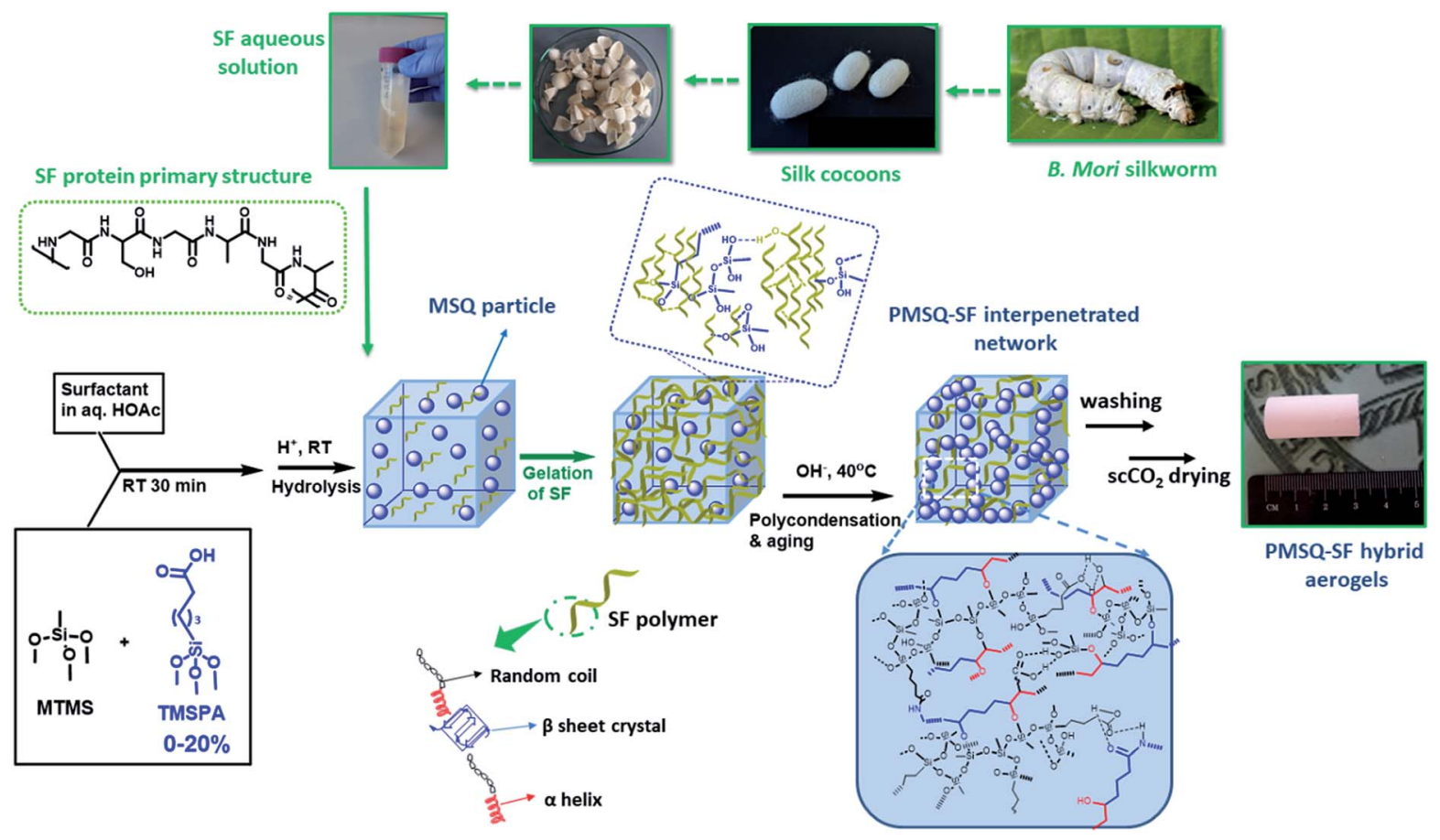

Scheme 1 Synthesis of PMSQ-SF hybrid aerogels.

hybrid series, the following sample labeling is used: PMSQ aerogels that are directly mixed with $\mathrm{SF}$ without coupling agent are labeled as EM-SF- $x$, where $x$ represents the SF mass fraction with respect to the silicon. Those composites that are prepared in the presence of the coupling agent, TMSPA, are labeled as EMT- $y$-SF- $x$, where $y$ represents the Si mol\% of TMSPA with respect to the total number of silicon centers. With these values, a broad range of PMSQ and SF contents are addressed.

For both aerogel hybrid series, we adopted a one-pot twostep acid-base sol-gel approach (Scheme 1) in which a sol of organosilanes (MTMS and TMSPA ( $0-20 \mathrm{~mol} \%$ of total silicon)) and SF was prepared in an aqueous acetic acid solvent (1.17 $\mathrm{mM}$ ) in the presence of hexadecyltrimethylammonium bromide (CTAB, $0.5 \mathrm{~g}$ ). The SF mass fraction was adjusted with respect to the total amount of silicon so that the SF : Si mass ratio for $[\mathrm{Si}]_{3.5}$ was $15: 100,40: 100$ and for $[\mathrm{Si}]_{17.5}$ was $1: 100,4: 100$, respectively. SF gelation occurs concurrent with an increase in sol viscosity (in $10 \mathrm{~min}$ ) and only in the second step after slow addition of $\mathrm{NH}_{4} \mathrm{OH}(1 \mathrm{~mL}, 2.8 \mathrm{wt} \%$ for EM (without TMSPA) and ( $1 \mathrm{~mL}, 28-30 \mathrm{wt} \%$ for EMT (with TMSPA)) polycondensation and gelation of the hydrolyzed organosilane species starts. The hybrid PMSQ-SF gels were aged in an oven $\left(40^{\circ} \mathrm{C}, 2 \mathrm{~d}\right)$. Byproducts were extracted by solvent exchange with methanol, followed by drying of the filigree wet gels by extraction with supercritical $\mathrm{CO}_{2}\left(T_{\mathrm{c}}=45{ }^{\circ} \mathrm{C}, P_{\mathrm{c}}=95\right.$ bar). For aerogel panels, the sol was cast in a medium sized Petri dish, and all other processing steps were the same as for cylindrical monoliths.

\section{Results and discussion}

As evident from the data in Table 1, physical crosslinking of SF proteins followed by supercritical drying results in ultra-light $\left(0.02 \mathrm{~g} \mathrm{~cm}^{-3}\right)$, soft and super-flexible (compressibility up to $80 \%$ strain), as well as micro-macroporous, SF aerogels with a relatively high surface area $>400 \mathrm{~m}^{2} \mathrm{~g}^{-1}$. These aerogels are obtained by a one-step aqueous-based acid-catalyzed sol-gel reaction and are the first SF aerogel monoliths hitherto reported. The assembly of SF by sol-gel processing partially leaves the $\beta$-sheet secondary conformations, as mechanically more stable conformation, thus giving the opportunity for building resilient and structurally stable functional materials. ${ }^{40}$ Based on this fact, the synergism of the peculiar properties of SF and PMSQ aerogels could result in hybrid materials with unique properties.

Table 1 details the starting compositions as well as some of the physical properties of the composite PMSQ-SF aerogels. We developed a simple, aqueous-based sol-gel strategy to modify the surface chemistry of PMSQ aerogels by co-condensing MTMS with an organofunctional silane carrying carboxylic acid functionality, TMSPM, that acts as a silane coupling agent to SF (Scheme 1). The SF polymer carries several amino acids with various functionalities, namely $-\mathrm{NH}_{2}, \mathrm{OH},-\mathrm{COOH},{ }^{42}$ allowing for interaction with the carboxylic acid group of TMSPM but also with surface silanol groups via robust covalent and non-covalent linkages.

Simultaneous gelation of the SF biopolymer and the organosilanes is challenging due to the different reaction rates, polarities, and mechanisms of gelation. Here, the interpenetrated network of PMSQ-SF is formed through two successive sol-gel reactions in which the gelation (physical cross-linking) of SF is initiated in dilute aqueous acidic media, in which, however, concurrently the hydrolysis and partial condensation of the organosilanes occurs. The gelation in SF is also concomitant with an increase in the viscosity of sol 
Table 1 Physical properties of PMSQ-SF hybrid aerogels and a pure silk aerogel for comparison

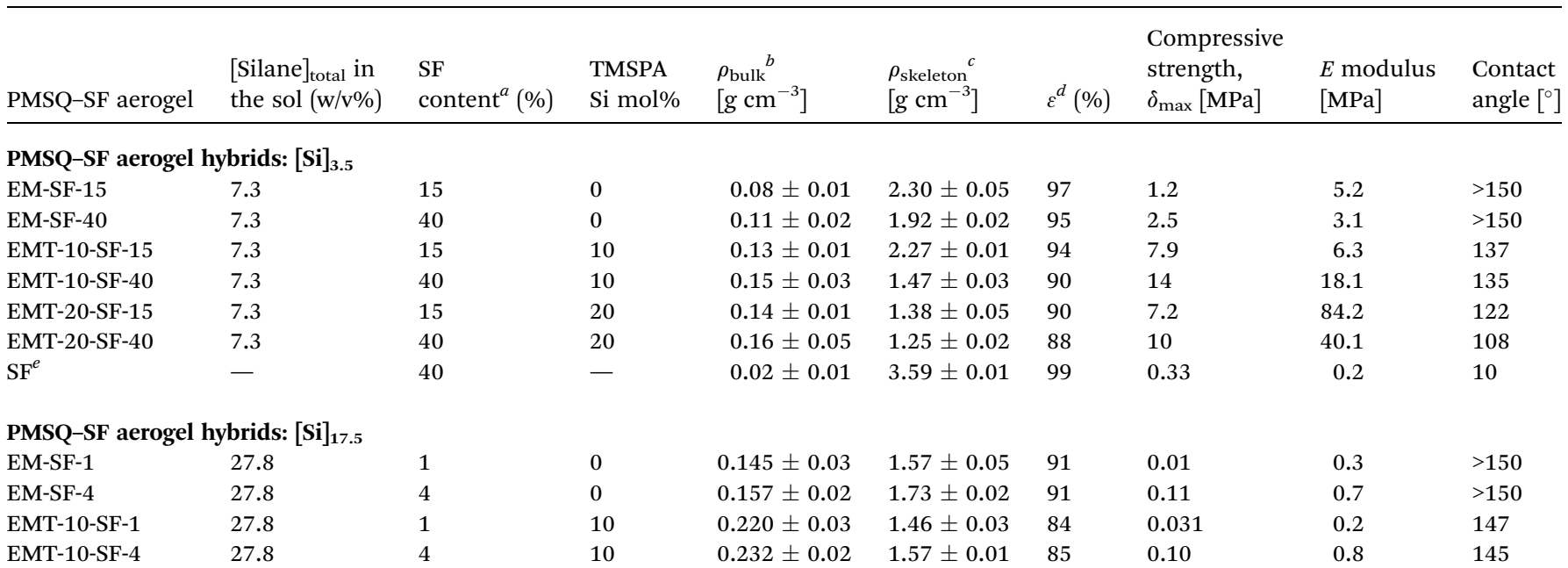

${ }^{a}$ SF content is reported with respect to the total silane in the sol mixture. ${ }^{b}$ Bulk $\left(\rho_{\text {bulk }}\right) \cdot{ }^{c}$ Skeleton $\left(\rho_{\text {skeleton }}\right)$ density. ${ }^{d}$ Porosity $(\varepsilon \%$, eqn $(\mathrm{S} 1))$ of synthesized hybrids. ${ }^{e}$ The pristine SF aerogel is called (AeroSF).

mixture. The true co-gelation of silk and organosilanes then takes place in the next step by addition of a base catalyst (see Scheme 1) in order to accelerate the gelation of the organosilane phase. For an efficient mixing of the organosilanes in the aqueous medium, and to inhibit macroscopic phase separation between hydrophobic silane species and the aqueous sol as well as SF, the cationic surfactant CTAB is added. As expected, a strong influence of TMSPA is recognized in the gelation process. While in formulations without TMSPA or with $<10 \%$, gelation of the organosilanes already occurs at the initial diluted acidic pH with longer gelation time (around 1 day), while higher contents of TMPSA require the addition of a base to yield stable monoliths. The homogeneity in the hybrid sol mixture is indicated by its transparent character. Upon gelation, the sol/gel turns opaque due to the phase separation of the hydrophobic PMSQ network from the aqueous medium, subsequently resulting in macroporosity.

In the following, we first address the consequences of mixing the different components of the porous structure, followed by a discussion of the chemical properties as well as homogeneity of the samples. In the last section, a more detailed view of the combination of physical properties is given.

\subsection{Structure}

The SEM images of the $[\mathrm{Si}]_{3.5}$ and $[\mathrm{Si}]_{17.5}$ hybrid series, with and without coupling agent (TMSPA) are given in Fig. 1(a) and (d), S1 and $\mathrm{S} 2 . \dagger$ In addition, images of a representative pure SF aerogel, an SF-free PMSQ aerogel (EM) and a carboxylic acid-modified SF-free PMSQ (EMT) aerogel are shown in Fig. 1(b) and (e). According to Fig. 1(b), the pure SF aerogels display a macroporous network of polymer "strands" or "nanofibers" with diameters of a few tens of nanometers. The pristine PMSQ aerogels, as also indicated elsewhere, ${ }^{\mathbf{1 9 4 3}}$ are composed of aggregates of colloidal particles interlinked in a pearl-necklacetype morphology (Fig. 1(e)). By the addition of co-precursor
TMSAP, a microscopic phase separation between the hydrophobic network of silane species and the polar solvent occurs, which results in a network with coarser domains and larger macropores (EMT-10, Fig. 1(e)). The $[\mathrm{Si}]_{3.5}$ hybrid series (Fig. 1(a) and S1 $\dagger$ ) shows a 3D bi-continuous network structure in which with increasing SF and TMSPA contents, phase separation occurs, resulting in a coarser network. ${ }^{43}$ The hierarchical porous structure is another characteristic of the $[\mathrm{Si}]_{3.5}$ hybrids, demonstrating a sponge-type macropore morphology with an average pore size of approximately $2 \mu \mathrm{m}$ and interconnecting mesopores. TEM micrographs of representative hybrid aerogels (EMT-10-SF-40) indicate the large crystalline domains of SF within the PMSQ network, which attributed to the presence of SILK I conformation having the antiparallel $\beta$-sheet crystals Fig. 1(c). The crystalline domains of SF within the PMSQ network are evident from the single crystal electron diffraction pattern with $d$-spacing of $\sim 4.3 \AA$, which is the characteristic of hydrogen-bonded chains into the $\beta$-sheet crystals in the (310) planes. ${ }^{44}$

In the case of $[\mathrm{Si}]_{17.5}$ hybrid gels (Fig. $1(\mathrm{~d})$ and $\mathrm{S} 2 \dagger$ ), in which the content of PMSQ is much higher compared to $[\mathrm{Si}]_{3.5}$, the network feature sizes are larger than $[\mathrm{Si}]_{3.5}$ hybrid series due to the high concentration of silanes in the initial sol mixture. In this series, a 3D open porous network consisting of particles with a globular fine aggregate morphology is obtained. In the presence of SF, fibrous structures are visible (EMT-10-SF-4) located between the PMSQ particles, indicating the presence of two interpenetrating continuous networks. Transmission electron microscope (TEM) micrographs of larger network secondary particles (approximately $2 \mu \mathrm{m}$ in the case of EMT-10) - Fig. 1(f) indicate, after sectioning the individual particle by ultramicrotomy, that the particles are composed of a microporous network of smaller nanoparticles (primary particles) with an average size less than $10 \mathrm{~nm}$. Different representative PMSQSF aerogel hybrids which are prepared in two different cylindrical or panel shapes are shown in Fig. 1(g). 


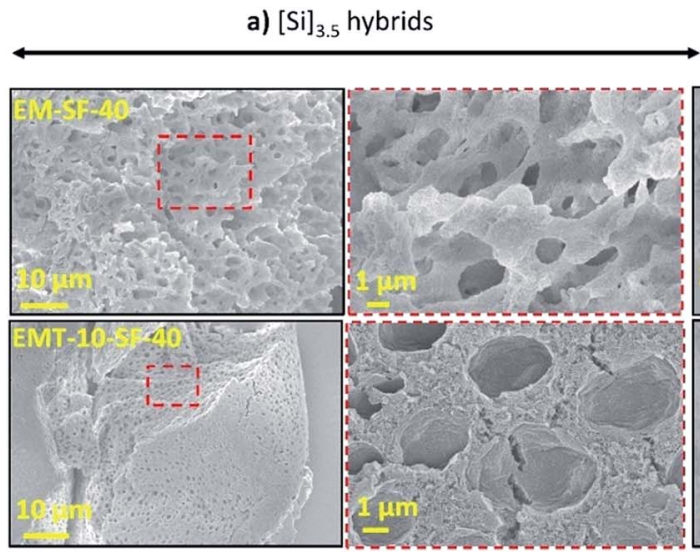

d) $[\mathrm{Si}]_{17.5}$ hybrids
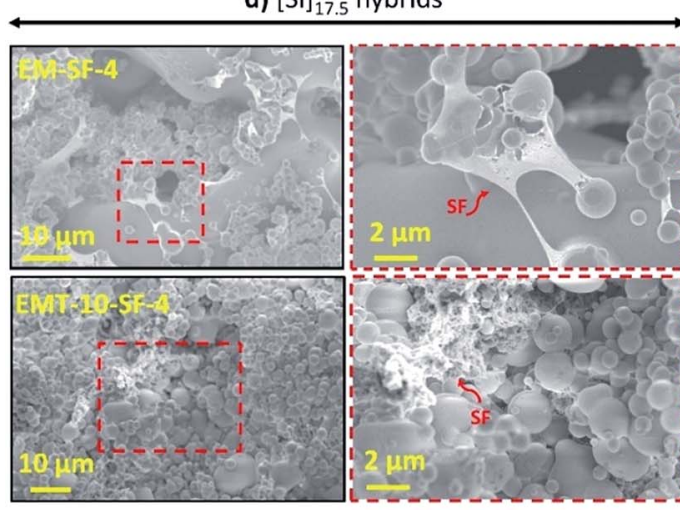

g) PMSQ-SF monoliths

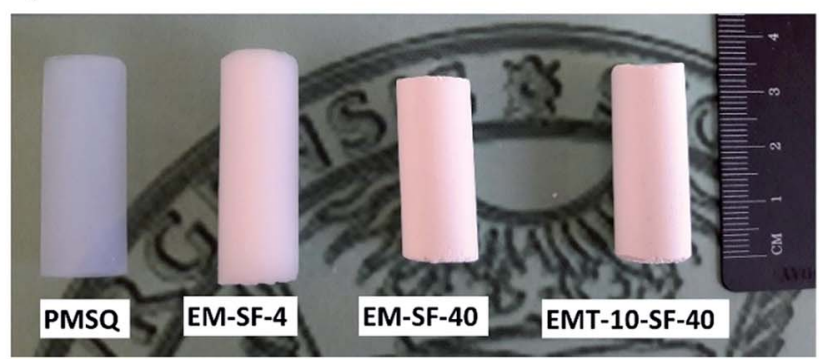

b) SF aerogel

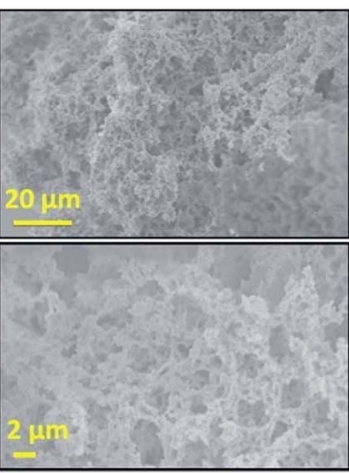

e) SF free aerogels

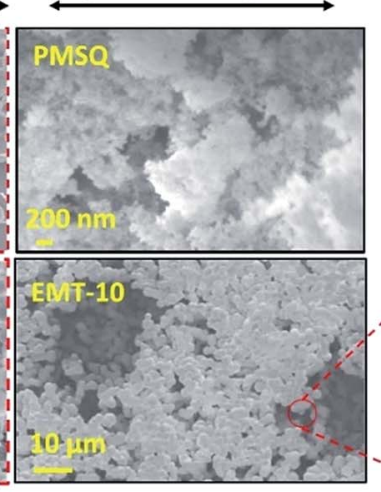

c) EMT-10-SF-40
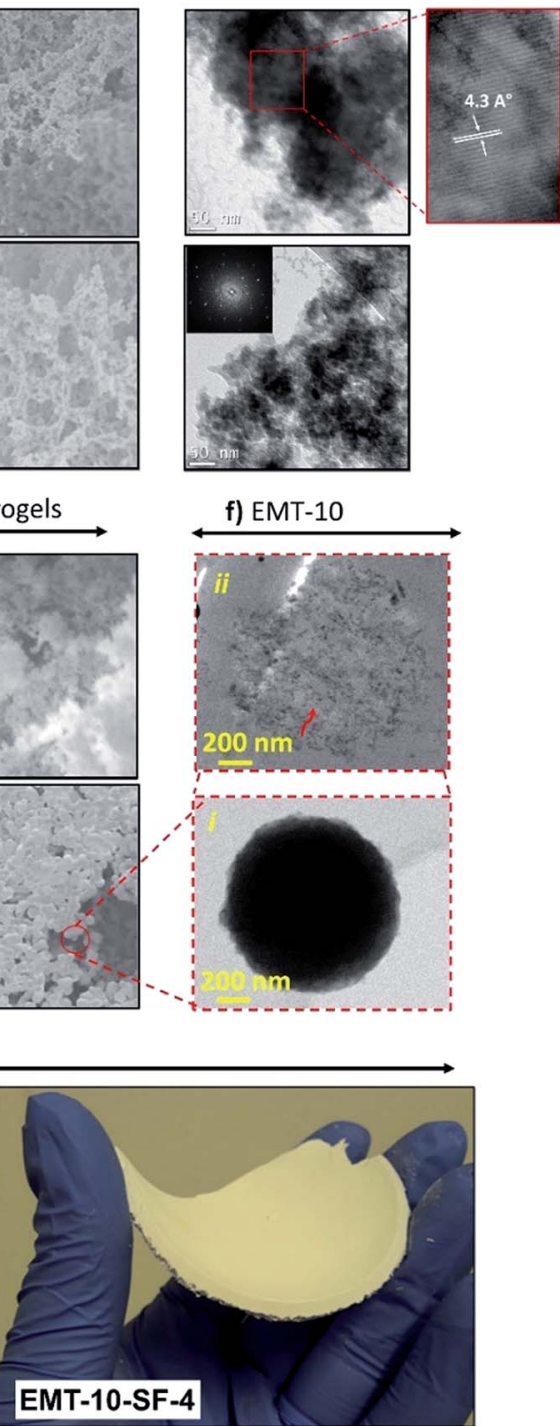

Fig. 1 (a) SEM micrographs of [Si] $]_{3.5}$ hybrid aerogel series, with and without coupling agent at different magnifications, (b) pure SF aerogel at different magnifications, (c) TEM micrographs of EMT-10-SF-40 aerogel hybrids, (d) SEM micrographs [Si] $]_{17.5}$ hybrid aerogel series with and without coupling agent at different magnifications, (e) SF free PMSQ (EM) and carboxylic-acid-modified PMSQ aerogels, and (f) TEM micrograph of an individual secondary particle of sample EMT-10 (i) and after sectioning a similar particle by ultramicrotome approach (ii), (g) the representative PMSQ-SF aerogel hybrids in two different shapes.

\subsection{Chemical composition and homogeneity}

To confirm the homogeneous chemical or physical mixing of PMSQ with the SF phase, the composition of a representative hybrid has been studied by several techniques. Both energy filtered TEM (EFTEM) and energy dispersive X-ray spectroscopy (EDX) confirm the presence of all key elements in both phases (Fig. 2). This is strong evidence for a homogeneous and fine dispersion of SF in PMSQ at a molecular and nanoscale level.

Fig. 3(a) shows the solid-state ${ }^{29}$ Si-MAS NMR spectra from PMSQ and carboxylic-acid-modified PMSQ aerogels indicating the successful linkage/co-condensation of TMSPA. The characteristic peaks for PMSQ (EM) are indexed as Tnm: T3m, $(\delta:-64$ $\mathrm{ppm})$, T2m, $(\delta:-54 \mathrm{ppm})$ where $n$ is the number of $\equiv \mathrm{Si}-\mathrm{O}-\mathrm{Si} \equiv$ bridges, while for carboxylic acid modified samples, EMT-10 and EMT-20, the extra peaks of TMSPA are indexed as Tnt: T3t $(\delta:-60 \mathrm{ppm}), \mathrm{T} 2 \mathrm{t}(\delta:-51 \mathrm{ppm})$. The expected resonances for TMSPA are also assigned in the solid-state ${ }^{13} \mathrm{C}$ MAS NMR spectra with a visible peak of the carboxyl groups $(\mathrm{COOH}, \delta: 178$ ppm) and the aliphatic carbons ( $\delta: 12.6,18,27.4$, and $33.7 \mathrm{ppm})$. In principle, many different possibilities can be expected for the interaction of SF and PMSQ (with and without TMSPA) based on hydrogen bonding, amide bonding, etc., and some of them are shown in Fig. S3.† SF contains various functionalities, due to the predominant presence of the four amino acids: glycine (Gly) ( $\sim 43-46 \%)$, alanine (Ala) $(\sim 25-30 \%)$ serine (Ser) $(\sim 12 \%)$ and tyrosine (Tyr) $(\sim 5 \%) .{ }^{45}$ Based on ATR-FTIR spectra (Fig. S4 $\dagger$ ) the 

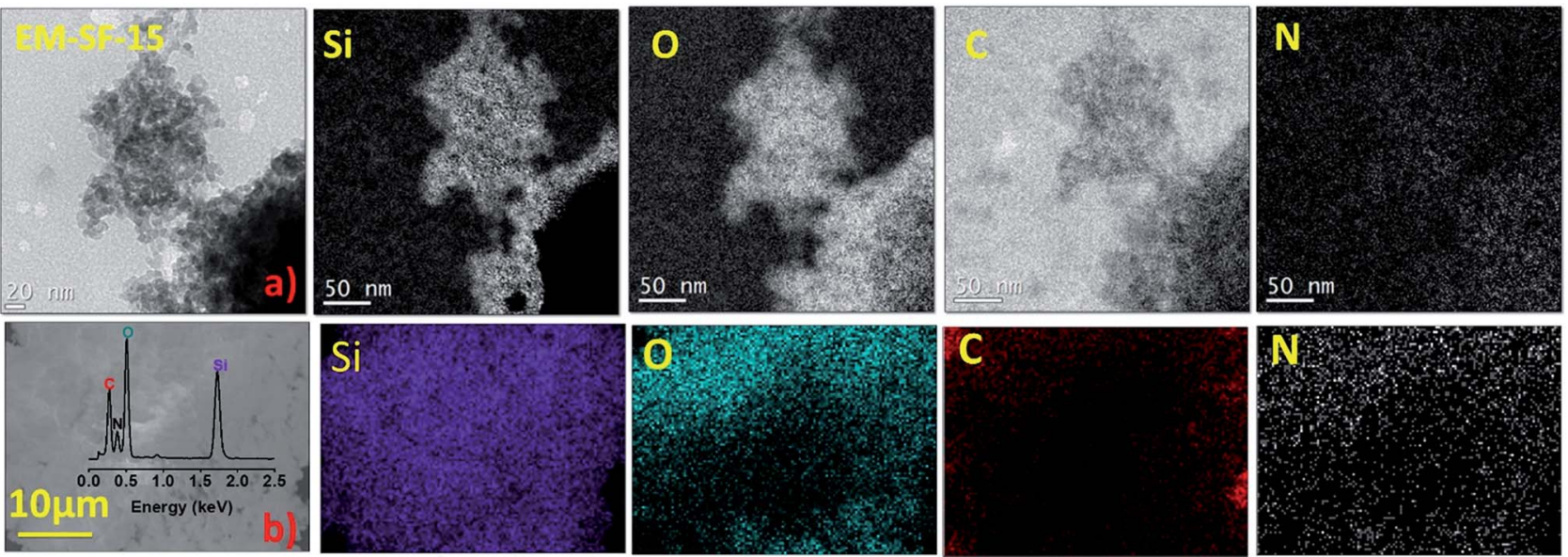

Fig. 2 (a) EFTEM analysis and (b) SEM-EDX maps of EM-SF-15.

peak intensity of the amide $\mathrm{I}\left(\nu_{\text {as }}(\mathrm{C}=\mathrm{O}): 1624 \mathrm{~cm}^{-1}\right)$ and amide II $\left(\delta \mathrm{s}(\mathrm{N}-\mathrm{H})\right.$ deformation: $\left.1517 \mathrm{~cm}^{-1}\right)$ for EMT-20-SF-15 is higher than the peak intensity of sample EM-SF-15. This is in agreement with the various interaction possibilities of the carboxylfunctionalized PMSQ phase with the SF polymer molecules through condensation of surface silanols with hydroxyl side chains of SF (for example with serine amino acids) or in more probable cases via amidic bonds, or several other noncovalent interactions, such as hydrogen bonding and dipole-dipole interactions. This strong interaction is also supported by the solid-state ${ }^{1} \mathrm{H}$ and ${ }^{13} \mathrm{C}$ MAS NMR spectra (Fig. 3(b) and (c), respectively). As can be seen from the solid-state ${ }^{1} \mathrm{H}$ NMR spectra (see Fig. 3(b)), in the case of the PMSQ sample free of coupling agent (EM-SF-15), due to the availability of silanol groups, condensation with hydroxyl side chain of SF is more predominant at $\delta: 4.3 \mathrm{ppm}$.

${ }^{1} \mathrm{H}^{29} \mathrm{Si}$ heteronuclear correlation (HETCOR) MAS NMR spectroscopy also confirms the molecular proximity of SF molecules to the PMSQ phase due to the coupling of SF protons with Si atoms in MTMS and TMSPA. For instance, in the case of a) Solid-state ${ }^{29} \mathrm{Si}$ MAS NMR

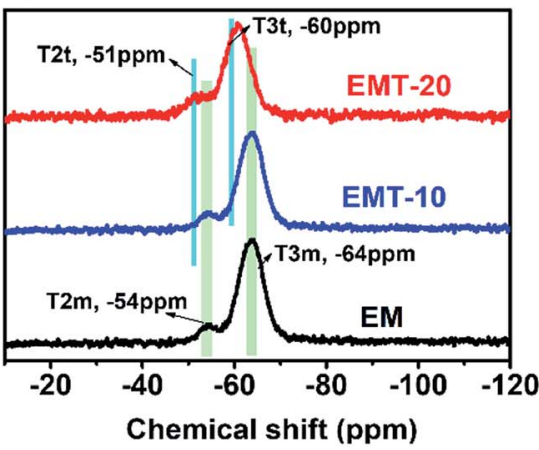

c) Solid-state ${ }^{13} \mathrm{C}$ MAS NMR

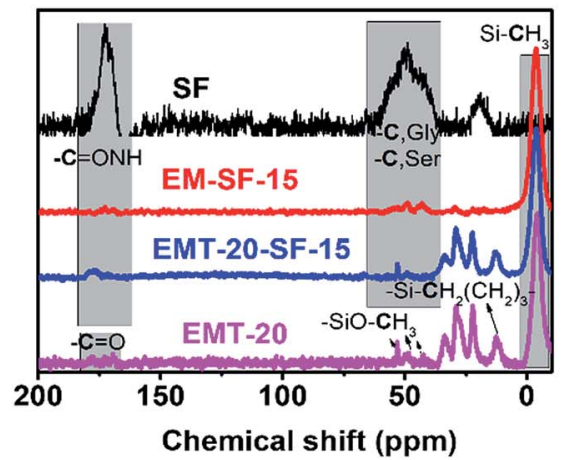

b) Solid-state ${ }^{1} \mathrm{H}$ MAS NMR

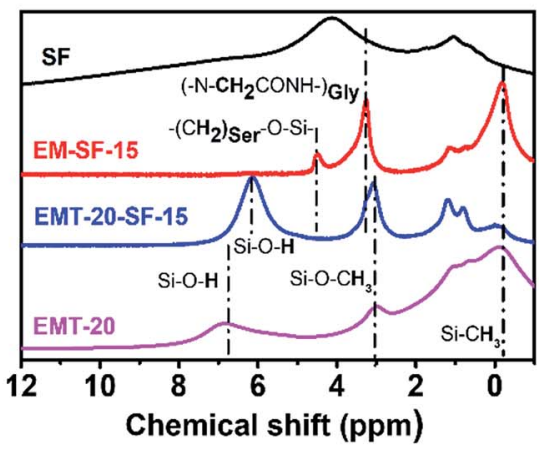

d) $\mathrm{N}_{2}$ sorption

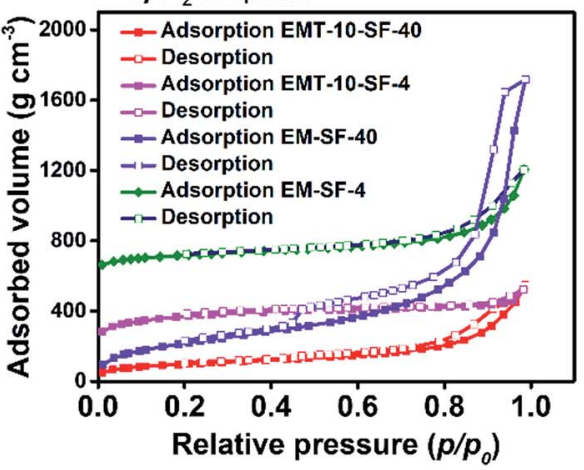

Fig. 3 Solid-state ${ }^{29} \mathrm{Si}-(\mathrm{a}),{ }^{1} \mathrm{H}$ - (b) and ${ }^{13} \mathrm{C}$ - (c) MAS NMR spectra of EM: PMSQ and carboxylic acid modified PMSQ and PMSQ-SF hybrid aerogels, (d) nitrogen adsorption-desorption isotherms of representative PMSQ-SF hybrid aerogels. 
EM-SF-15 (see Fig. 4(a)), the correlation of methylene protons in the side chain of SF (serine, $-\mathrm{CH}_{2} \mathrm{O}-$ ) with silicon atoms (T3m) shows a cross-peak which is evidence for mixing of both phases through covalent linkages $\left(e . g\right.$. $\equiv \mathrm{Si}-\mathrm{O}-\mathrm{CH}_{2}-, \delta: 4.3 \mathrm{ppm}\left({ }^{1} \mathrm{H}\right.$ NMR)). However, due to the lower accessibility of surface silanol groups in EMT-10-SF-15 (see Fig. 4(b)) such interactions are less probable or might overlap with other cross-peaks caused by the correlation of silicon peaks (T3m) and the proton of the methoxy group in the surface- $\mathrm{SiOCH}_{3}(\delta: 3.47 \mathrm{ppm})$.

\subsection{Physical, thermal and mechanical properties}

By comparing the textural and structural properties, it is evident that the overall concentration of alkoxysilane is a key parameter in density values and other textural and physical features of the samples (Table 1). As expected the bulk density is lower for $[\mathrm{Si}]_{3.5}$ samples (see Table 1 ) and increases with higher amounts of SF and coupling agent in the composites. However, the densities are comparable with those in previously reported composites such as silica-cellulose nanofiber (CNF), ${ }^{28,29}$ silicachitosan $^{32,33}$ and silica-pectin ${ }^{31}$ composites, for which only simple tetrafunctional organosilanes have been used as silicon sources. As it is evident from the nitrogen sorption isotherms of selected samples in Fig. 3(d) and S5, $\uparrow$ all composites have a type IV isotherm with capillary condensation occurring at $p / p_{0}>0.4$, confirming that almost all hybrids have a mesoporous character. For samples with coupling agents (EMT-20 series), relatively narrow hysteresis loop occurs, which is indicative of the lower mechanical deformation of the samples during desorption/drying the liquid nitrogen condensed in the capillaries, therefore confirming the stiffness of these hybrid materials.

The surface area and the average pore diameter of aerogel hybrids are obtained from the nitrogen sorption data. However, due to the possible mechanical deformation, during the desorption/drying of the liquid $\mathrm{N}_{2}$, experienced by the aerogel samples in the desorption branch of the capillary condensation range, the pore volume $\left(V_{\text {pore }}\right)$ and average pore diameter $\left(D_{\text {pore }}\right)$ determined by Barrett-Joyner-Halenda (BJH) or density functional theory (DFT) is not entirely reliable. Therefore, we reported the $V_{\text {pore }}$ and $D_{\text {pore }}$ calculated by eqn (S2) and (S3) $\uparrow$ for entirety - see Table 2 . As seen from the data in Table 2, the EMSF-15 aerogels exhibit a high $S_{\mathrm{BET}}=900 \mathrm{~m}^{2} \mathrm{~g}^{-1}$, which apparently decreases with increasing the SF loading and TMSPA
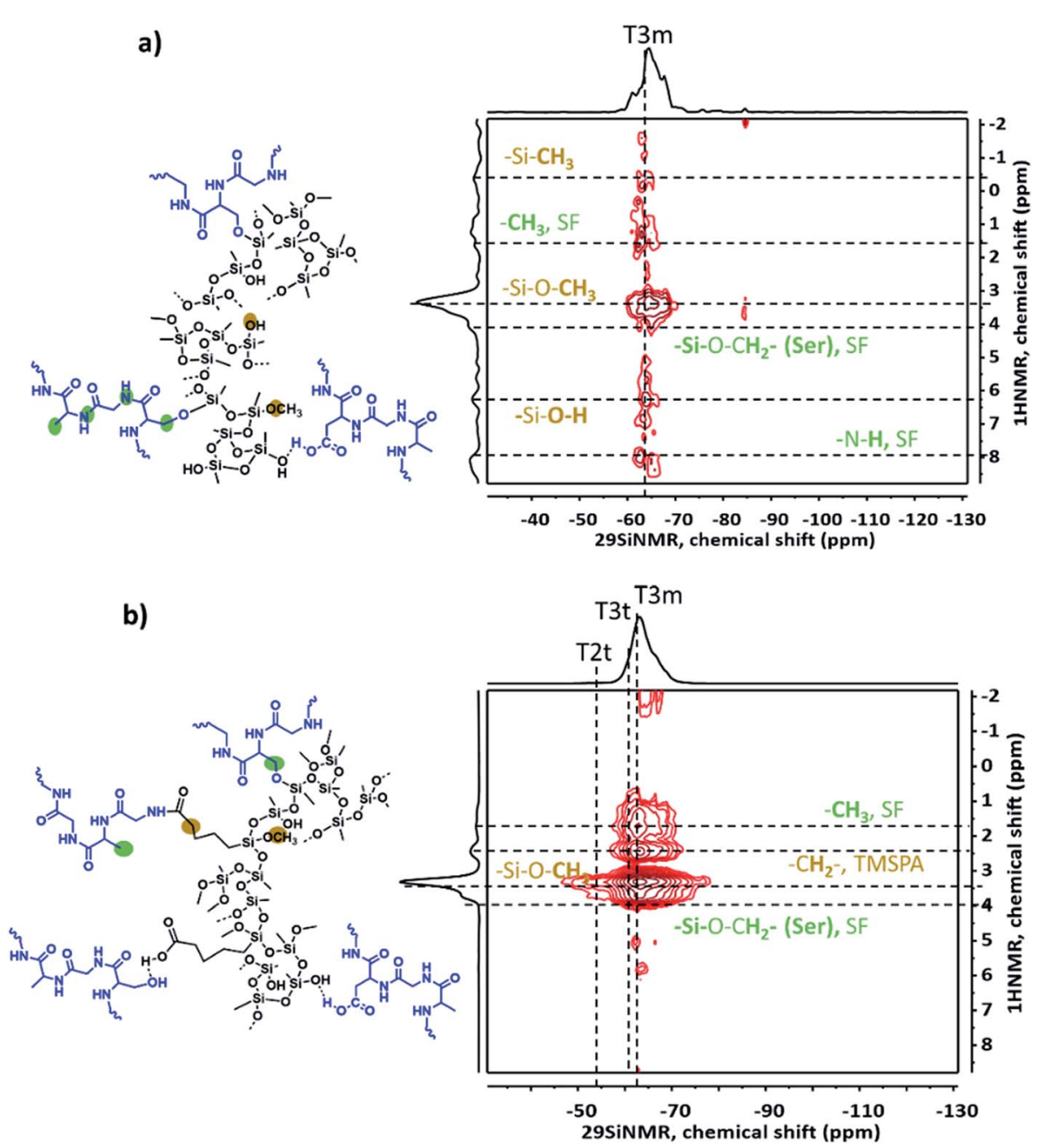

Fig. $4{ }^{1} \mathrm{H}-{ }^{29}$ Si heteronuclear correlation MAS NMR spectroscopy of (a) EM-SF-15, (b) EMT-10-SF-15. 
concentration. Meanwhile, the mean pore diameter increases from $53.6 \mathrm{~nm}$ for EM-SF-15 to $68.5 \mathrm{~nm}$ for EMT-20-SF-40. As also seen from SEM micrographs, the aerogel with higher SF and TMSPA loadings exhibits large pores and aggregated particles, which results from the macroscopic phase separation of the hydrophobic condensates of silane species and formation of SF $\beta$-sheet crystals during the sol-gel and hybridization reaction. The average pore diameter $\left(D_{\text {pore }}\right)$ of all hybrids in this study are placed below the mean free path of the air under ambient conditions (70 nm, STP), which together with their low density, suggesting that the materials should display very low gas and solid thermal conductivity.

The mechanical behavior of these aerogels is an essential property for almost all the applications. Typical stress-strain curves of PMSQ-SF aerogel hybrids are shown in Fig. 5(a), (b) and (d)-(f). It is evident that almost all PMSQ-SF hybrid series of $[\mathrm{Si}]_{3.5}$, with SF contents of 15 and $40 \%$, can sustain the compressive stresses up to $80 \%$ of strain without failure (Table 1, Fig. 5(a)). Also, the hybrids exhibit a typical linear elastic region at lower strain (Fig. 5(b)) and a densification region at higher strain. In addition, the mechanical behavior and density of the hybrids strongly depend on the SF loading and the presence of the coupling agent. It is evident from Fig. 5(c) that the presence of TMSPA predominantly increases the final strength $\left(\delta_{\max }\right)$ as well as the elastic modulus $(E)$ of samples upon compression, while $\mathrm{SF}$ increases the maximum compressibility or elasticity $\left(\varepsilon_{\max }\right)$. Moreover, the EMT-10-SF-40 aerogel hybrid is in the optimum range for the desired mechanical functionality, as this is the highest maximum strength and elasticity with a moderate density of $0.15 \mathrm{~g} \mathrm{~cm}^{-3}$ obtained. The viscoelastic hysteresis of EMT-10-SF-40 during loading and unloading up to the maximum strain of $50 \%$ indicates partial recovery after exposure for one day to $>85 \% \mathrm{RH}$ and $30{ }^{\circ} \mathrm{C}$ (Fig. 5(d)), resulting in a relatively small degree of network deformation. This is promising and indicates that the PMSQ-SF hybrid aerogel could display a high degree of breathability, similar to traditional cellulose foam as well as

Table 2 BET specific surface area $\left(S_{\mathrm{BET}}\right)$, pore volume $\left(V_{\text {pore }}\right)$ and average pore diameter $\left(D_{\text {pore }}\right)$

\begin{tabular}{llcc}
\hline Aerogel & $S_{\mathrm{BET}}{ }^{a}\left[\mathrm{~m}^{2} \mathrm{~g}^{-1}\right]$ & $V_{\text {pore }}{ }^{b}\left[\mathrm{~cm}^{3} \mathrm{~g}^{-1}\right]$ & $D_{\text {pore }}{ }^{c}[\mathrm{~nm}]$ \\
\hline$[\text { Si }]_{3.5}$ & & & \\
EM-SF-15 & 900 & 10.9 & 53.6 \\
EM-SF-40 & 506 & 8.1 & 64.0 \\
EMT-10-SF-15 & 812 & 6.9 & 33.9 \\
EMT-10-SF-40 & 354 & 5.8 & 66.6 \\
EMT-20-SF-15 & 732 & 6.4 & 35.1 \\
EMT-20-SF-40 & 335 & 5.7 & 68.5 \\
SF & 412 & 49.7 & 482.7 \\
& & & \\
[Si $]_{17.5}$ & & & \\
EM-SF-1 & 646 & 6.3 & 38.7 \\
EM-SF-4 & 427 & 5.8 & 16.7 \\
EMT-10-SF-1 & 920 & 3.8 & 23.8 \\
EMT-10-SF-4 & 618 & 3.7 &
\end{tabular}

${ }^{a}$ Specific surface area $\left(S_{\mathrm{BET}}\right) .{ }^{b}$ Pore volume $\left(V_{\text {pore }}\right.$, eqn (S2)). ${ }^{c}$ Pore diameter $\left(D_{\text {pore }}\right.$, eqn (S3)). recently reported ultralight anisotropic graphene oxide-cellulose based nanocomposites. ${ }^{\mathbf{4 6}}$ With the same procedure, the optimized hybrid sample of $[\mathrm{Si}]_{17.5}$ (EMT-10-SF-4) also exhibits very good resilience even up to $\varepsilon=60 \%$ for several loading and unloading cycles as shown in Fig. 5(e). It is also shown that $[\mathrm{Si}]_{3.5}$ hybrid aerogels displayed a larger ultimate strain $\left(\varepsilon_{\max }=\right.$ $70-80 \%)$ and final compressive strength $\left(\delta_{\max }\right)(1.2-14 \mathrm{MPa})$ compared to the $[\mathrm{Si}]_{17.5}$ series, which contain $\varepsilon_{\max }$ of $\leq 60 \%$ and very low $\delta_{\max }$ of 10-100 kPa (Fig. 5(f)). Therefore, as shown in Fig. $5(\mathrm{~g})$, the $[\mathrm{Si}]_{3.5}$ aerogel hybrids demonstrate a larger resiliency, compressibility, and durability than aerogels with $[\mathrm{Si}]_{17.5}$.

Overall, the deformability and good mechanical resilience for the PMSQ-SF aerogel hybrids can be ascribed to the highly flexible hydrocarbon chain of TMSPA and ( $\mathrm{Si}-\mathrm{O}-\mathrm{Si}$ ) siloxane bonds of PMSQ, as well as to the high viscoelastic SF biopolymer which creates a continuous network within the PMSQ network and supports the delicate network structure. The mechanical behavior for PMSQ-SF aerogel hybrids is not only limited to cylindrical monoliths, but the material can also be processed in thin panels $(1 \mathrm{~cm}$ thickness $\times 15 \mathrm{~cm}$ diameter $)$ with very good flexibility (see Fig. 1(g)).

The power law relationship between the bulk density $\left(\rho_{\mathrm{b}}\right)$ and Young's modulus $(E)$ is plotted in Fig. S6(a) and (b) $\dagger$ with an exponent $b(1)$ of $3.84\left(R^{2}=0.85\right)$ for $[\mathrm{Si}]_{3.5}$ and, $4.28\left(R^{2}=0.76\right)$ for $[\mathrm{Si}]_{17.5}$ hybrid aerogels, which are similar to those reported for PU, ${ }^{47}$ PU-silica, ${ }^{48}$ cellulose-silica ${ }^{29}$ and pectin-silica composite aerogels. ${ }^{31}$ Strongly depending on the synthesis route and network connections, the power law relationships between modulus and density for silica aerogels are reported with an exponent of 3 to 3.7. ${ }^{4-51}$ The increased exponent for aerogels reported in this work is most likely due to the variations of the molecular structure upon integrating SF with PMSQ, which contributes to an extension in the network connections and variations in the skeletal structures.

Thermal stability is another fundamental property for most high-performance applications of aerogels. Thermogravimetric analysis (see TG-DTA curves for [Si $]_{3.5}$ in Fig. S7†) indicates that the PMSQ-SF hybrids are stable up to $350{ }^{\circ} \mathrm{C}$, while SF, the alkyl moieties in the coupling agent (TMPSA), and the methyl groups decompose at around 353, 537, and $670{ }^{\circ} \mathrm{C}$, respectively. Therefore, the hybrid developed here is more thermally stable than the other hybrid aerogel counterparts prepared from other biopolymers like cellulose and pectin. ${ }^{29,31}$

\subsection{Wettability}

PMSQ-SF aerogels are superhydrophobic but also superoleophilic for both $[\mathrm{Si}]_{3.5}$ and $[\mathrm{Si}]_{17.5}$ samples by presenting a high water contact angle $\left(\theta>150^{\circ}\right.$, without coupling agent) (see Table 1), irrespective of SF contents. Water droplets are hardly attainable on the surface of EM-SF-4 and EM-SF-40, and both samples remain completely dry after they are taken out of the water (see Fig. 6(a)), which reflects the homogenous mixing of PMSQ moieties with polar SF polymers at entire gel structure. Also, water jets can bounce off the surface of these samples without leaving a trace ( $v d$. Fig. 6(a)). Despite excellent water droplet repellency, EM-SF-4 and EM-SF-40 can be easily wetted by organic solvents especially those with low surface tension. The 
(a)

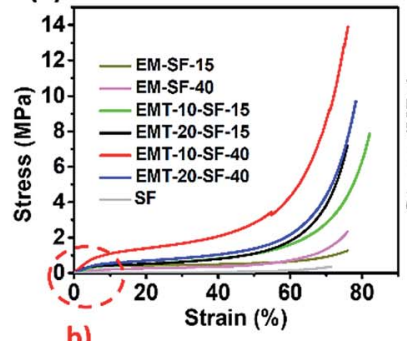

b)

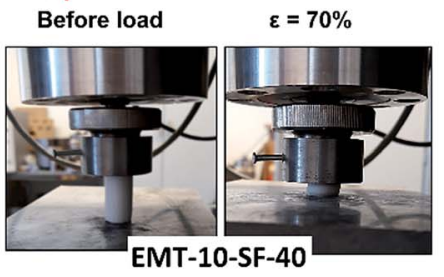

(b)

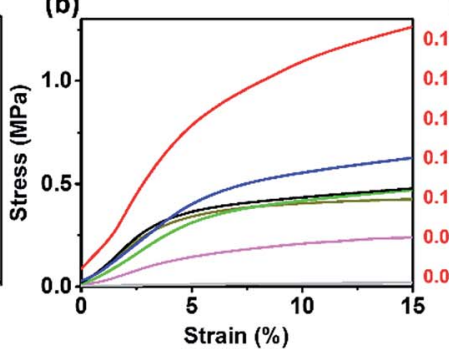

(e)

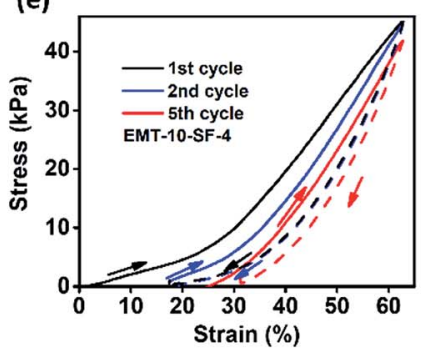

(c)

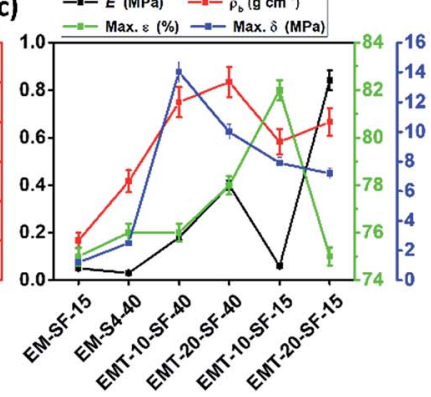

(d)

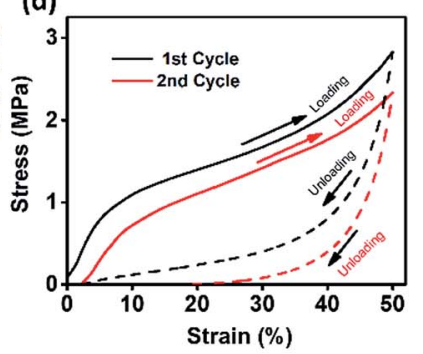

(g)

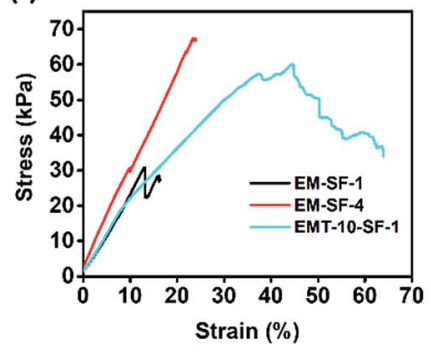

Fig. 5 (a) Stress-strain curves of PMSQ-SF monoliths for [Si] $]_{3.5}$ with the compressive behaviour, (b) the stress-strain curves for [Si] $]_{3.5}$ in a low strain, (c) the variation of Young' modulus $(E)$, bulk density $\left(\rho_{\mathrm{b}}\right)$, maximum strain $\varepsilon(\%)$, and max. compressive strength $\left(\delta_{\max }\right)$ versus SF and TMSPA content for [Si] 3.5 series of PMSQ-SF monoliths, (d) the compressive hysteresis of EMT-10-SF-40 at maximum strain of $50 \%$ in two successive compressive cycles, (e) the compressive hysteresis of EMT-10-SF-4 at maximum strain of $60 \%$ in five cycles, (f) stress-strain curves of PMSQ-SF monoliths for $\left[\mathrm{Si}_{17.5}, \mathrm{~g}\right.$ ) the variation in the maximum strength of representative developed hybrid aerogels.

contact angle of the organic solvents and oils on these samples are $0^{\circ}$, and the wetting pits are immediately formed by dripping these solvents on the aerogel. This unique wettability of these samples is ascribed to the presence of $-\mathrm{Si}-\mathrm{CH}_{3}$ moieties in the PMSQ surface skeleton, the high surface roughness, and the low surface energy, which produce a poor wettability of water.

By the addition of only $10 \%$ coupling agent to the composites, EMT-10-SF-4 and EMT-10-SF-40, a minor compromise on the surface hydrophobicity occurs $\left(135^{\circ}<\theta<145^{\circ}\right)$ : the droplets of water remain stable on the surface even after several minutes. The samples also exhibit a high oleophilicity towards organic solvents and oils (Fig. 6(b) and (c)). The small hydrophilicity in these samples is attributed to the incorporation of the polar carboxylic acid moieties in the overall network surface (as the long hydrocarbon group of TMSPA would be pushed out to the network surface due to the spatial confinement ${ }^{13}$ inside the gel network skeleton) and the presence of partial surface-Si-OH as a result of the possible incomplete condensation of TMSPA during the in situ sol-gel reaction.

As expected this unique wettability of PMSQ-SF aerogels towards the water and insoluble organic solvents makes these aerogels ideal candidates for selective oil-water separation. As shown in Fig. 6(d), EM-SF-40, is placed in water (dyed with methylene blue (MB))/vegetable oil solution. It exhibits a selective absorption ability towards the vegetable oil thus obtaining clean water.

\subsection{Organic solvents absorption capacity and reusability}

Due to the high porosity, low density, superhydrophobicity, and superoleophilicity together with the fibrillar structure of
SF in the PMSQ-SF aerogel, these aerogels could be utilized for the absorption of various organic solvents from water. Fig. 7(a) presents the absorption capacities of several representative PMSQ-SF aerogel hybrids for a list of different organic solvents and oils. It is evident that the PMSQ-SF aerogels

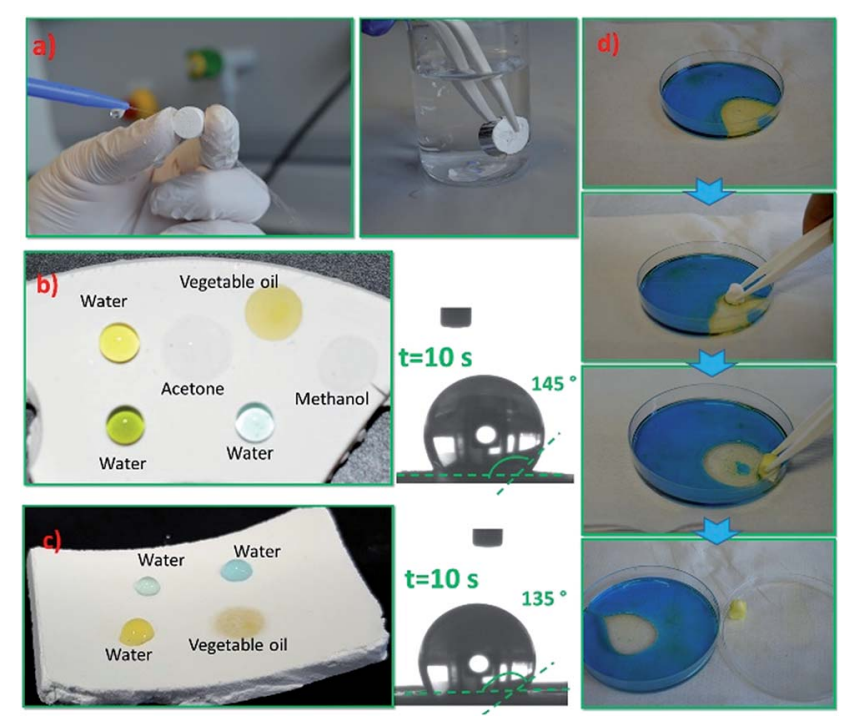

Fig. 6 (a) Superhydrophobic behaviour in both EM-SF-4 and EM-SF40 aerogels, (b) and (c) show the surface wettability of the EMT-10-SF4 and EMT-10-SF-40, respectively, with water, vegetable oil, methanol and acetone and the respective water contact angles, (d) photographs show the selective absorption of vegetable oil by the EM-SF-40 aerogel due to its superhydrophobicity and superoleophilicity. Note: the Petri dish is oleophilic. 
achieve a weight capacity (absorbed liquid per weight of aerogel) of over $2500 \%$ for the absorption of all solvents and obtain a maximum of $2644 \%$ for the absorption of dimethylformamide (DMF). As expected, the overall absorption capacities of EM-SF-40 and EMT-10-SF-40 are superior to those of EM-SF-4 and EMT-10-SF-4 due to the lower density and higher porosity $(\varepsilon \sim 91-95 \%)$ in the former aerogels providing more space to accommodate the organic solvents. It is also seen from Fig. 7(b) that the absorption capacities of PMSQ-SF aerogels are much higher than those for other reported absorbents from synthetic polymer $\left(14-57 \mathrm{~g} \mathrm{~g}^{-1}\right),^{52}$ superhydrophobic/superoleophobic cotton $\left(20-50 \mathrm{~g} \mathrm{~g}^{-1}\right){ }^{53}$ nanocellulose (20-185 $\left.\mathrm{g} \mathrm{g}^{-1}\right),{ }^{54,55}$ MTMS-DMDMS aerogel $\left(500-1500 \mathrm{~g} \mathrm{~g}^{-1}\right)^{20}$ and superhydrophobic silica aerogel $\left(16 \mathrm{~g} \mathrm{~g}^{-1}\right)^{56}$ but comparable with that of very recently reported polymeric nanofibrous (PVA-co-PE) aerogel (2500-5000 $\left.\mathrm{g} \mathrm{g}^{-1}\right) .{ }^{57}$ In addition, the developed PMSQ-SF aerogels indicate some reusability towards the low viscous and volatile organic solvents such as methanol and acetone in five absorption cycles. In this regard, the removal of the chosen solvents from the corresponding PMSQ-SF aerogels between the cycles only required a gentle compression and drying for 0.5 hours with a very low degree of aerogel network disintegration after the $5^{\text {th }}$ cycle (Fig. $7(\mathrm{c})$ ). Although due to the higher porosity and lower density in EMSF-40 and EMT-10-SF-40, a higher initial absorption capacity compared to those of EM-SF-4 and EMT-10-SF-4 is obtained, while the latter aerogels indicated a small compromise in the absorption capacity during the next absorption cycles. This is because these aerogels show a minimal shrinkage upon drying from the solvent of the first cycle and therefore the porosity and the absorption capacity subsequently were reduced in the initial cycles and then became constant. The absorption capacities and weight after drying between the cycles for EM-SF-4 and EMT-10-SF-4 for both methanol and acetone during all absorption cycles remained almost constant.

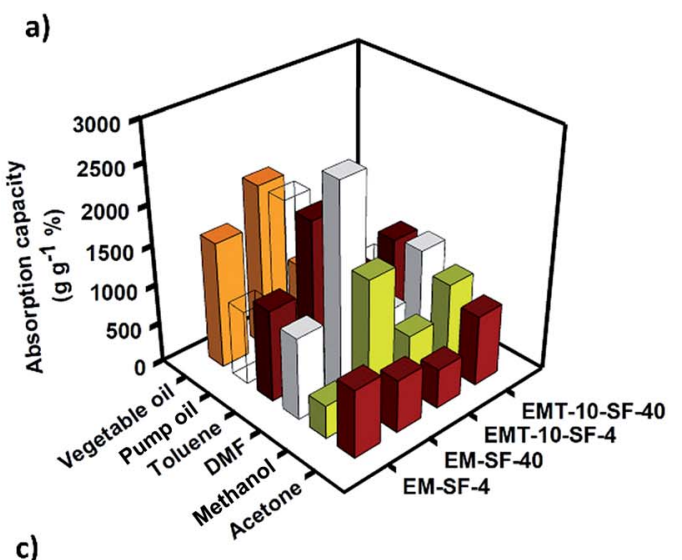

b)

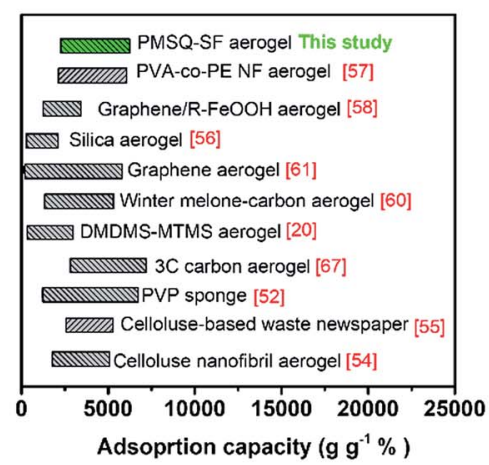

c)
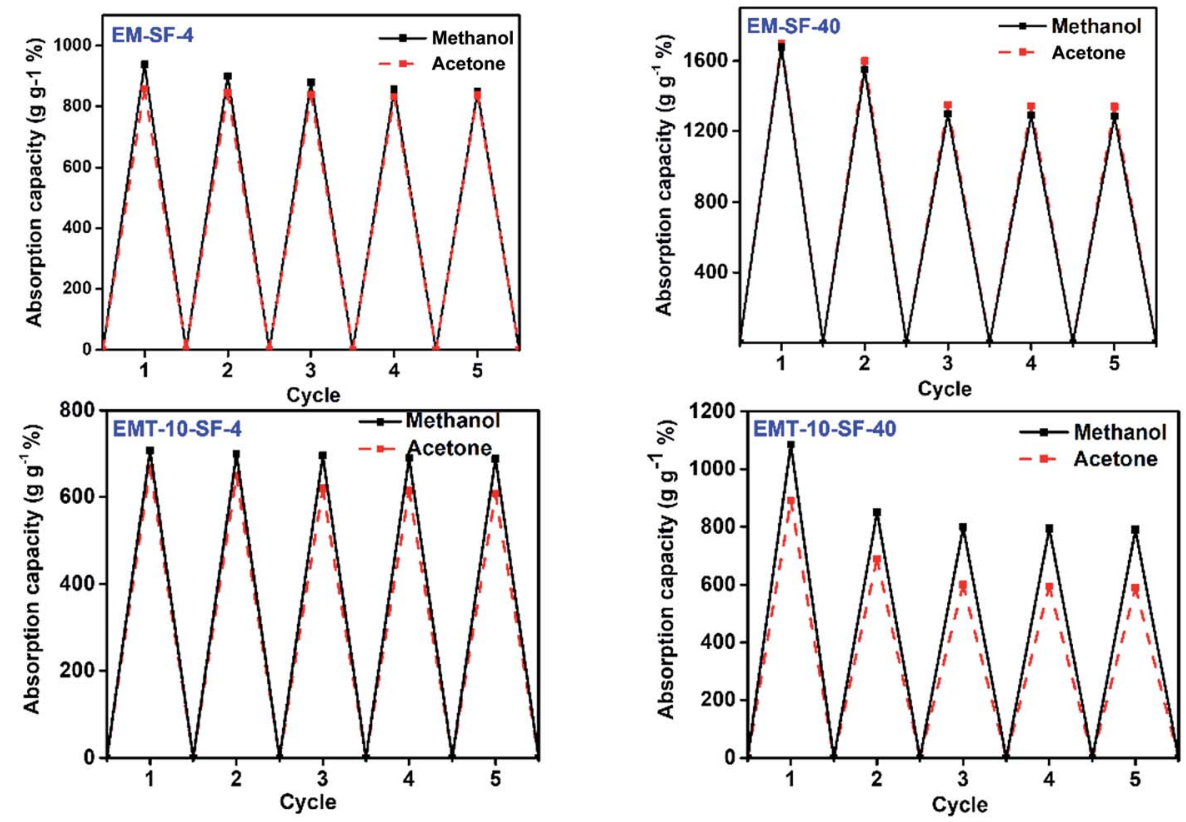

Fig. 7 (a) The respective absorption capacities of PMSQ-SF aerogels for different oils and organic solvents, (b) comparison of the absorption capacity of PMSQ-SF aerogel for different organic pollutants with the other previously reported aerogel-based absorbers, (c) cyclic absorption test for methanol and acetone. ${ }^{20,52,54-61}$ 


\subsection{Oil absorption kinetics}

The extent of surface hydrophobicity and variation of the microstructure, as well as absorption temperature and oil/ organic solvent viscosity all have a major influence on the absorption kinetics. ${ }^{62}$ We used vegetable oil as a model absorbate to study the absorption kinetics of selected PMSQ-SF aerogels at room temperature $\left(23^{\circ} \mathrm{C}\right)$. Two different kinetic theories were applied to the experimental data shown in Fig. $\mathrm{S} 8 \dagger$ in order to model/estimate the rate constants. These two pseudo-first and pseudo-second order models ${ }^{63,64}$ are commonly used for oil absorption. In this study, we use both models to fit the experimental absorption data.

The pseudo-first order equation in its linear form can be expressed as: ${ }^{62}$

$$
\ln \frac{Q_{\mathrm{m}}}{Q_{\mathrm{m}}-Q_{t}}=k_{1} t
$$

where $Q_{\mathrm{m}}\left(\mathrm{g} \mathrm{g}^{-1}\right)$ is the maximum oil absorption, $Q_{t}$ is the oil absorption at time $t$, and $k_{1}$ is the absorption rate constant which is determined from the slope of the $\ln \left[Q_{\mathrm{m}} /\left(Q_{\mathrm{m}}-Q_{t}\right)\right]$ versus $t$ plot.

The pseudo-second order equation can be expressed in a linear form as: ${ }^{62}$

$$
\frac{t}{Q_{t}}=\frac{1}{Q_{\mathrm{m}}} t+\frac{1}{k_{2} Q_{\mathrm{m}}{ }^{2}}
$$

By plotting $\left(t / Q_{t}\right)$ versus $t$, the absorption rate constant $k_{2}$ can be determined.

From the plots of Fig. S9(a and b), $\dagger$ the sorption rate constants $k_{1}, k_{2}$ and the correlation coefficient $R^{2}$ are calculated and presented in Table 3.

The pseudo first-order model can be used in various absorption systems, e.g. close to the equilibrium as well as systems with time-independent solute concentration or linear equilibrium absorption isotherm. ${ }^{64}$ The pseudo second-order model is used to explain absorption processes that are mostly controlled by chemisorption. ${ }^{65,66}$

As is evident from Fig. 8, the correlation coefficient values of the pseudo second-order model match the data for the tested oil better than those of the pseudo first-order model, confirming that the pseudo second-order model allows a better prediction of the oil absorption behavior of the majority of the aerogels in this work, except for EM-SF-4 which shows better correlation for both models. The absorption rate constant $k_{2}$ for the vegetable oil in EM-SF-40 is higher than those of the other aerogels, which means that the oil absorption by this aerogel occurs faster due to its low density and high porosity.

\subsection{Gravity-driven and continuous oil-water separation}

The piece of PMSQ-SF aerogel could be used for gravity-driven separation of water/oil (vegetable oil) mixtures. In the process of separation, we dyed the water using MB for the clear observation, which is quite a prevalent method. ${ }^{67}$ As shown in Fig. 9(a) and Movie S1, $\dagger$ once the mixture solution came in contact with the piece of PMSQ-SF (EM-SF-40) aerogel that was fixed in the glass tube, the vegetable oil wetted the aerogel and permeated through it; however, water was filtered out because of the superhydrophobicity/oleophilicity in the aerogel without using any driving force just the weight of the water/oil mixture. The oil separation efficiency was determined by staining of the oil phase with Oil Red $\mathrm{O}$ dye which has a characteristic absorption peak at $530 \mathrm{~nm}$. The UV-vis spectrum of the filtrate showed no traces of Oil Red $\mathrm{O}$ absorption after five filtrations (Fig. S10†) confirming the complete removal of the oil by the hybrid aerogels. The flux of the oil/water mixture through the aerogel was calculated based on the flow volume per unit time from the used area of the aerogel. The EM-SF-40 aerogel exhibited a flux of $3333 \mathrm{~L} \mathrm{~m}^{-2} \mathrm{~h}^{-1}$, which was higher than that of waste paper-based carbon aerogel with a flux of $995 \mathrm{~L} \mathrm{~m}^{-2}$ $\mathrm{h}^{-167}$ and those of the commercial membranes. ${ }^{68,69}$

In addition, a very simple experiment was conducted to testify the continuous separation of water from free oil (vegetable oil) using the EM-SF-40 as an absorbent, with a vacuum pump. As shown in Fig. 9(b) and Movie S2, $\uparrow$ a piece of EM-SF-40 aerogel monolith was fixed to the end of a micropipette tip that was connected to a container and a vacuum pump using a silicone tube. In a lower pressure and at a relatively lower volume of the free oil in the water surface, the water could be pump into the receiver via the silicone tube, and simultaneously the EMSF-40 could absorb/trap the residual free oil until the absorption equilibrium is reached. However, previous studies ${ }^{57,67}$ used the same experiment to continuously pump the free oil/organics into the receiver through aerogel specimen and leaving out the pure water in the original flask. To the best of our understanding, the separation mechanism can be adjusted by tuning the vacuum pressure and the amount of free oil in the water mixture. In this study, the experiments can also be performed in such way to continuously pump the free oil to the receiver, in this case, the separation is sometimes unsatisfactory with some droplets of water in the received oils as the pressure to separate the oil from water is relatively high. Generally speaking, by

Table 3 Summary of the maximum oil absorption capacities and the absorption rate constants of the PMSQ-SF aerogels at $23^{\circ} \mathrm{C}$ using pseudofirst and -second order models

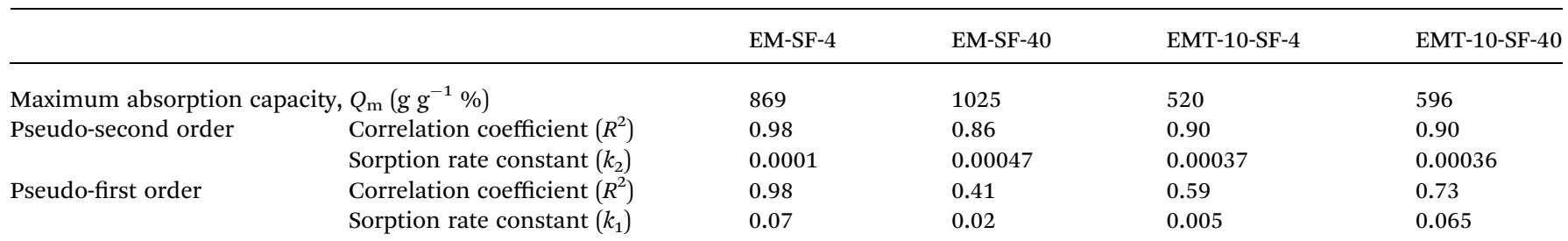



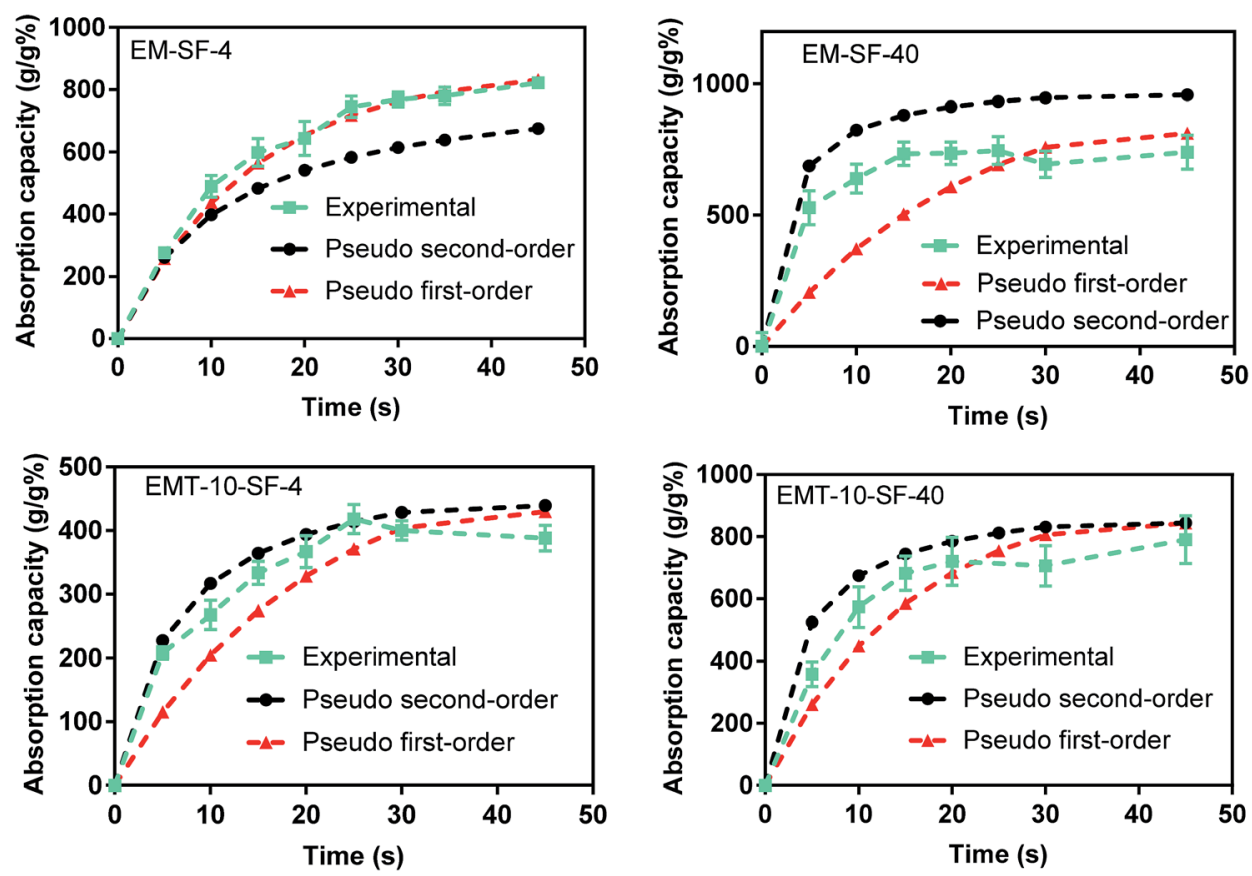

Fig. 8 Experimental data fitted with the pseudo-first and -second order models for the absorption kinetics of vegetable oil onto the PMSQ-SF aerogels at $23^{\circ} \mathrm{C}$.

increasing the external pressure the fast separation is feasible. However the large external pressure may cause damage to the porous structure ${ }^{57}$ of the aerogel specimen. In brief, these results demonstrate that some formulations of PMSQ-SF aerogels are ideal absorbents for continuous separation of oil from water with an external pump, thanks to their
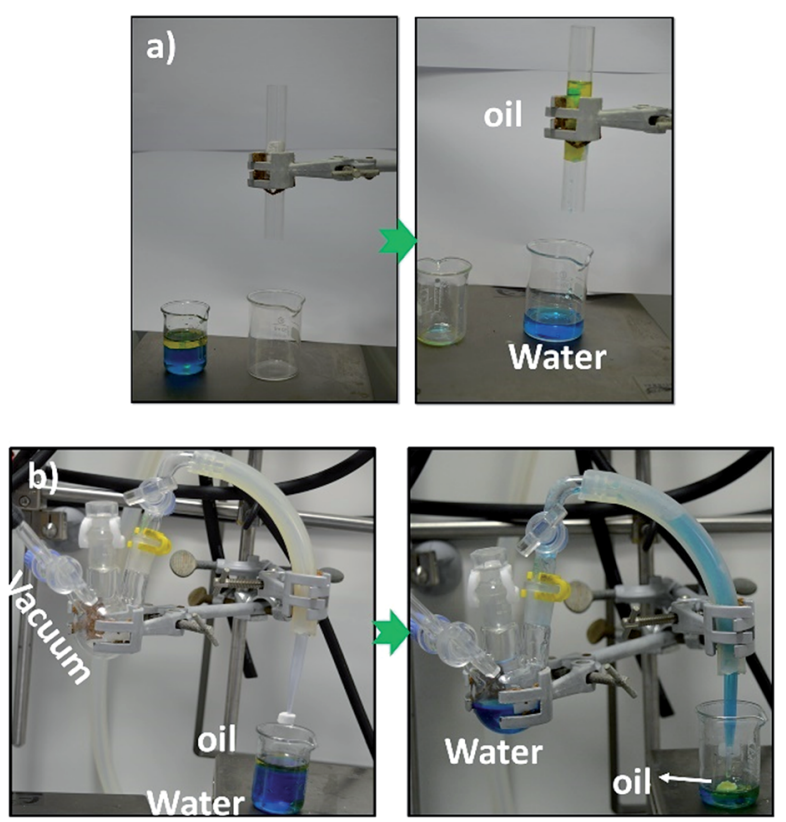

Fig. 9 (a) Gravity-driven separation of vegetable oil from water, (b) continuous separation of water from oil using a simple device. The continuous collection of (MB dyed) water $(12 \mathrm{~mL})$ from oil $(3 \mathrm{~mL})$ with a piece of EM-SF-40 aerogel $(1 \mathrm{~cm} \times 1 \mathrm{~cm})(\mathrm{vd}$. Movie $\mathrm{S} 2 \dagger)$. superhydrophobicity, oleophilicity and very good mechanical properties.

\subsection{Thermal insulation, stability in the harsh environment and fire retardancy}

Due to the ultra-light density and high porosity of aerogels, they are increasingly drawing attention for high-performance thermal insulation materials in various domains. Fig. 10(a) presents the total thermal conductivity of different representative PMSQ-SF aerogel hybrids. It is seen that the PMSQ-SF aerogel have a thermal conductivity $(\lambda)$ of 0.032 to $0.043 \mathrm{~W} \mathrm{~m}^{-1} \mathrm{~K}^{-1}$. The thermal insulation property of PMSQ-SF aerogel hybrids is superior to those of previously reported polymer reinforced silica aerogels $\left(\lambda=0.045-0.07 \mathrm{~W} \mathrm{~m}^{-1} \mathrm{~K}^{-1}\right)^{70}$ and even better than those of currently used insulators such as polystyrene foam $(\lambda=$ 0.03-0.06 $\left.\mathrm{W} \mathrm{m}^{-1} \mathrm{~K}^{-1}\right) .^{71}$ The pore size of all representative PMSQ-SF aerogels is located in the mesopore regime (see Table 2). Therefore, almost all the aerogels favor the Knudsen effect, which implies that the air circulation is confined inside the pores thus resulting in lower gas conduction. Moreover, EMSF-40 and EMT-10-SF-40 possess relatively lower densities than EM-SF-4 and EMT-10-SF-4, thus presenting better insulation performance. The thermal conductivity of pure silk fibroin aerogel is as low as $0.026 \mathrm{~W} \mathrm{~m}^{-1} \mathrm{~K}^{-1}$ which is the first superinsulator aerogel from the silk fibroin biopolymer, also named as "AeroSF", ${ }^{72}$ hitherto reported. The thermal insulation performance of AeroSF is also comparable with that of pectin aerogel, Aeropectin $\left(\lambda \geq 0.020 \mathrm{~W} \mathrm{~m}^{-1} \mathrm{~K}^{-1}\right) .^{73}$

We have also investigated how the dimensional stability and mechanical behavior are affected when the PMSQ-SF aerogel hybrids (EM-SF-40) are subjected to successive cryogenic 

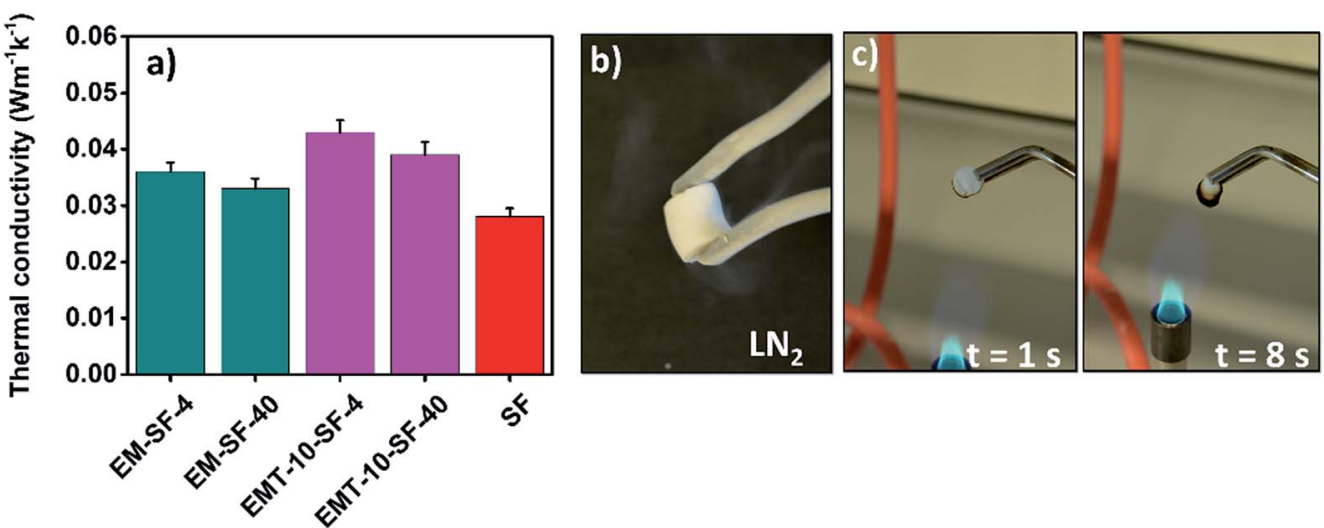

Fig. 10 (a) Thermal conductivity of some representative PMSQ-SF aerogel hybrids, (b) EM-SF-40 after immersing in the LN 2 , (c) burning behavior of the EM-SF-40 with time.

temperature, liquid nitrogen $\left(\mathrm{LN}_{2}\right)$, and elevated temperature $\left(100{ }^{\circ} \mathrm{C}\right)$. As is seen from the Table S1, $\dagger$ when EM-SF-40 was immersed in the $\mathrm{LN}_{2}$ ( $v d$. Fig. 10(b)) for 1 minute and then exposed to $100{ }^{\circ} \mathrm{C}$ in an oven for 1 hour, minor compromise with regard to the sample mass and compressive strength could occur. Thus, this behavior would qualify the PMSQ-SF aerogel for application in the rigorous environments such as thermally insulating materials required for space exploration.

Traditional fossil-fuel insulating materials are easily ignitable and therefore require the addition of flame retardants. ${ }^{74,75}$ Most of the flame-retardant materials, like halogenated and phosphorous compounds, have a negative impact on health and the environment. ${ }^{76}$ The silica and PMSQ aerogels are known as fire retardant materials. ${ }^{75,77}$ Another advantage of PMSQ-SF aerogel hybrids is their fire-retardant behavior due to the homogenous mixing of silk fibroin biopolymer and the PMSQ network in overall aerogel composite. Fig. 10(c) demonstrates the vertical burning of PMSQ-SF aerogel (EM-SF-40) which displayed excellent fire retardancy without self-propagation of the flame, and resulted in a carbonized residue with almost similar shape and dimension as the original aerogel. The pure silk fibroin aerogel displayed low fire retardancy and shrunk upon burning ( $v d$. Fig. S11†).

\section{Conclusions}

To conclude, we successfully developed a novel class of mechanically robust, micro-macroporous, light-weight and superhydrophobic/oleophilic PMSQ-SF hybrid aerogels through a simple, green and one pot strategy with excellent water-oil separation and thermal insulation performance. As far as we know, the developed synthesis method is the first report on the formation of hybrid aerogels by exploiting the hybridization of methylsilsesquioxane with the low-cost SF biopolymer extracted from silkworm cocoons. The formed hybrid monoliths show a number of extraordinary physical properties such as very low densities, high surface areas, and improved mechanical properties.

In this study, the primary focus was on tailoring the surface chemistry of PMSQ by using a coupling agent (TMSPA) that is able to interact with a protein-based polymer of SF and thus allowing for mixing the superhydrophobic silsesquioxane network with the hydrophilic biopolymer phase. In this regard, homogeneous mixing of the two phases at the molecular level has been obtained through carefully controlling the gelation behavior of the different components. It has been shown that the addition of the coupling agent to the methyltrimethoxysilane sol-gel mixture results in distinct changes in the network build-up. Substantial changes in the porous structure are also obtained when the SF phase is mixed in. To get a high level of control on the homogeneity, the sol-gel reaction was pursued in a two-step approach, in which first, the SF protein was gelled and only in a second step, by changing the $\mathrm{pH}$ value, the silane network was condensed. ${ }^{1} \mathrm{H}^{29} \mathrm{Si}$ heteronuclear correlation NMR spectroscopy in combination with detailed compositional studies by various other techniques confirmed a successful homogeneous linkage/mixing of SF to PMSQ at the molecular level. The hierarchically organized, porous PMSQ-SF aerogels show a very low density of $0.08-0.15 \mathrm{~g} \mathrm{~cm}^{-3}$ in addition to a high compressive strength up to $14 \mathrm{MPa}$ and compressibility up to $80 \%$ strain along with excellent bending flexibility and viscoelasticity in different compressive cycles. Meanwhile, the representative PMSQ-SF hybrid aerogels demonstrate superhydrophobicity/oleophilicity $\left(\theta>150^{\circ}\right.$ for water) which provide them with excellent organic pollutants/oil separation from water with remarkable absorption capacities (500-2644\% weight gain), recyclability for some solvents as well as continuous separation of contaminants from water. It is worth noting that the PMSQ-SF aerogel hybrids also display very good thermal insulation performance $\left(\lambda=0.032\right.$ to $\left.0.043 \mathrm{~W} \mathrm{~m}^{-1} \mathrm{~K}^{-1}\right)$, fire retardancy and stability in the rigorous environment.

Together with the excellent processability, these unique multifunctional gels are expected to further extend the practical applications of this class of porous compounds.

To this end, the high performance multifunctional hybrid PMSQ-SF hybrid aerogels of this study interestingly can be prepared in such a way to utilize the silk fibroin cocoon of the textile industry's biomass or waste, and therefore it would be a great attempt toward the mass reduction and greener environment with less carbon footprint. 


\section{Conflicts of interest}

There are no conflicts to declare.

\section{Acknowledgements}

Hajar Maleki acknowledges financial support by the Austrian FWF for the Lise Meitner fellowship (project number: M2086N34). Transmission electron microscopy, TEM, was carried out using facilities at the University Service Centre for Transmission Electron Microscopy, Vienna University of Technology, Austria. Lawrence Whitmore acknowledges financial support from Interreg Österreich-Bayern 2014-2010 Project AB29 Synthese, Charakterisierung und technologische Fertigungsansätze für den Leichtbau "n2m" (nano-to-macro). We gratefully acknowledge the help of Karin Whitmore in the preparation of ultramicrotome specimens.

\section{References}

1 S. S. Kistler, Nature, 1931, 127, 741.

2 N. Hüsing and U. Schubert, Angew. Chem., Int. Ed., 1998, 37, 22-45.

3 M. M. Koebel, A. Rigacci and P. Achard, in Aerogels Handbook, ed. M. A. Aegerter, N. Leventis and M. M. Koebel, 2011, pp. 607-633.

4 J. P. Randall, M. A. B. Meador and S. C. Jana, ACS Appl. Mater. Interfaces, 2011, 3, 613-626.

5 G. Zu, T. Shimizu, K. Kanamori, Y. Zhu, A. Maeno, H. Kaji, J. Shen and K. Nakanishi, ACS Nano, 2018, 12, 521-532.

6 H. Maleki and N. Hüsing, Appl. Catal., B, 2018, 221, 530-555.

7 H. Maleki, Chem. Eng. J., 2016, 300, 98-118.

8 J. E. Amonette and J. Matyáš, Microporous Mesoporous Mater., 2017, 250, 100-119.

9 Z. Wu, L. Zhang, J. Li, X. Zhao and C. Yang, RSC Adv., 2018, 8, 5695-5701.

10 H. Maleki, L. Durães, C. A. García-González, P. del Gaudio, A. Portugal and M. Mahmoudi, Adv. Colloid Interface Sci., 2016, 236, 1-27.

11 J. Stergar and U. Maver, J. Sol-Gel Sci. Technol., 2016, 77, 738752.

12 A. C. Pierre and G. M. Pajonk, Chem. Rev., 2002, 102, 42434265.

13 Y. Zhang, J. Wang and X. Zhang, J. Colloid Interface Sci., 2018, 515, 1-9.

14 J. Wang, Y. Zhang, Y. Wei and X. Zhang, Microporous Mesoporous Mater., 2015, 218, 192-198.

15 J. Wang, Y. Zhang and X. Zhang, J. Mater. Chem. A, 2016, 4, 11408-11415.

16 H. Maleki, L. Durães and A. Portugal, J. Non-Cryst. Solids, 2014, 385, 55-74.

17 A. Soleimani Dorcheh and M. H. Abbasi, J. Mater. Process. Technol., 2008, 199, 10-26.

18 A. Venkateswar, R. Sharad, D. Bhagat, H. Hirashima and G. M. Pajonk, J. Colloid. Interface Sci., 2006, 300, 279-285.

19 K. Kanamori, M. Aizawa, K. Nakanishi and T. Hanada, Adv. Mater., 2007, 19, 1589-1593.
20 G. Hayase, K. Kanamori, M. Fukuchi, H. Kaji and K. Nakanishi, Angew. Chem., Int. Ed., 2013, 52, 1986-1989.

21 G. Hayase, K. Kanamori and K. Nakanishi, J. Mater. Chem., 2011, 21, 17077-17079.

22 N. Leventis, Acc. Chem. Res., 2007, 40, 874-884.

23 N. Leventis, C. Sotiriou-Leventis, G. Zhang and A.-M. M. Rawashdeh, Nano Lett., 2002, 2, 957-960.

24 J. Wang, J. Kuhn and X. Lu, J. Non-Cryst. Solids, 1995, 186, 296-300.

25 A. Karout, P. Buisson, A. Perrard and A. C. Pierre, J. Sol-Gel Sci. Technol., 2005, 36, 163-171.

26 M. A. B. Meador, S. L. Vivod, L. McCorkle, D. Quade, R. M. Sullivan, L. J. Ghosn, N. Clark and L. A. Capadona, J. Mater. Chem., 2008, 18, 1843-1852.

27 C.-Y. Kim, J.-K. Lee and B.-I. Kim, Colloids Surf., A, 2008, 313314, 179-182.

28 J. Cai, S. Liu, J. Feng, S. Kimura, M. Wada, S. Kuga and L. Zhang, Angew. Chem., Int. Ed., 2012, 51, 2076-2079.

29 S. Zhao, Z. Zhang, G. Sebe, R. Wu, R. V. Rivera Virtudazo, P. Tingaut and M. M. Koebel, Adv. Funct. Mater., 2015, 25, 2326-2334.

30 A. Demilecamps, G. Reichenauer, A. Rigacci and T. Budtova, Cellulose, 2014, 21, 2625-2636.

31 S. Zhao, W. Malfait, A. Demilecamps, Y. Zhang, S. Brunner, L. Huber, P. Tingaut, A. Rigacci, T. Budtova and M. M. Koebel, Angew. Chem., Int. Ed. Engl., 2015, 54, 14282-14286.

32 S. Takeshita and S. Yoda, Nanoscale, 2017, 9, 12311-12315.

33 S. Zhao, W. J. Malfait, E. Jeong, B. Fischer, Y. Zhang, H. Xu, E. Angelica, J. W. M. Risen, J. W. Suggs and M. M. Koebel, ACS Sustainable Chem. Eng., 2016, 4, 5674-5683.

34 S. Zhao, W. J. Malfait, N. Guerrero-Alburquerque, M. M. Koebel and G. Nyström, Angew. Chem., Int. Ed., 2018, DOI: 10.1002/ange.201709014.

35 G. Hayase, K. Kanamori, K. Abe, H. Yano, A. Maeno, H. Kaji and K. Nakanishi, ACS Appl. Mater. Interfaces, 2014, 6, 94669471.

36 W. J. Malfait, S. Zhao, R. Verel, S. Iswar, D. Rentsch, R. Fener, Y. Zhang, B. Milow and M. M. Koebel, Chem. Mater., 2015, 27, 6737-6745.

37 D. N. Rockwood, R. C Preda, T. Yücel, X. Wang, M. L. Lovett and D. L. Kaplan, Nat. Protoc., 2011, 6, 1612-1631.

38 F. G. Omenetto and D. L. Kaplan, Science, 2010, 329, 528531.

39 R. R. Mallepally, M. A. Marin, V. Surampudi, B. Subia, R. R. Rao, S. C. Kundu and M. A. McHugh, Biomed. Mater., 2015, 10, 035002.

40 P. Tseng, B. Napier, S. Zhao, A. N. Mitropoulos, M. B. Applegate, B. Marelli, D. L. Kaplan and F. G. Omenetto, Nat. Nanotechnol., 2017, 12, 474-480.

41 A. Feinle, S. Flaig, M. Puchberger, U. Schubert and N. Hüsing, Chem. Commun., 2015, 51, 2339-2341.

42 A. R. Murphy and D. L. Kaplan, J. Mater. Chem., 2009, 19, 6443-6450.

43 C. R. Ehgartner, S. Grandl, A. Feinle and N. Hüsing, Dalton Trans., 2017, 46, 8809-8817. 
44 S.-J. He, R. Valluzzi and S. P. Gido, Int. J. Biol. Macromol., 1999, 24, 187-195.

45 C. Z. Zhou, F. Confalonieri, M. Jacquet, R. Perasso, Z. G. Li and J. Janin, Proteins, 2001, 44, 119-122.

46 B. Wicklein, A. Kocjan, G. Salazar-Alvarez, F. Carosio, G. Camino, M. Antonietti and L. Bergström, Nat. Nanotechnol., 2015, 10, 277-283.

47 A. Bang, C. Buback, C. Sotiriou-Leventis and N. Leventis, Chem. Mater., 2014, 26, 6979-6993.

48 Y. Duan, S. C. Jana, B. Lama and M. P. Espe, Langmuir, 2013, 29, 6156-6165.

49 R. W. Pekala, L. W. Hrubesh, T. M. Tillotson, C. T. Alviso, J. F. Poco and J. D. Lemay, presented in part at the Materials Research Society, MRS Symposium, Boston, 1990.

50 T. Woignier, J. Reynes, A. Hafidi, A. Beurroies and J. Phalippou, J. Non-Cryst. Solids, 1998, 241, 45-52.

51 J. Fricke and A. Emmerling, J. Sol-Gel Sci. Technol., 1998, 13, 299-303.

52 Y. Pan, K. Shi, C. Peng, W. Wang, Z. Liu and X. Ji, ACS Appl. Mater. Interfaces, 2014, 6, 8651-8659.

53 F. Liu, M. Ma, D. Zang, Z. Gao and C. Wang, Carbohydr. Polym., 2014, 103, 480-487.

54 A. Mulyadi, Z. Zhang and Y. Deng, ACS Appl. Mater. Interfaces, 2016, 8, 2732-2740.

55 S. Han, Q. Sun, H. Zheng, J. Li and C. Jin, Carbohydr. Polym., 2016, 136, 95-100.

56 M. Shi, C. Tang, X. Yang, J. Zhou, F. Jia, Y. Han and Z. Li, RSC Adv., 2017, 7, 4039-4045.

57 Q. Liu, J. Chen, T. Mei, X. He, W. Zhong, K. Liu, W. Wang, Y. Wang, M. Liab and D. Wang, J. Mater. Chem. A, 2018, 6, 3692-3704.

58 Y. Zhan, J. Wang, K. Zhang, Y. Li, Y. Meng, N. Yan, W. Weia, F. Peng and H. Xia, Chem. Eng. J., 2018, 34, 184-193.

59 Y. H. Zhan, N. Yan, Y. C. Li, Y. Y. Meng, J. Wang, N. Zhang, Q. Yu and H. S. Xia, Chem. Eng. J., 2017, 327, 142-149.
60 Y.-Q. Li, Y. A. Samad, K. Polychronopoulou, S. M. Alhassan and K. Liao, ACS Sustainable Chem. Eng., 2014, 2, 1492-1497.

61 Y. Luo, S. Jiang, Q. Xiao, C. Chen and B. Li, Sci. Rep., 2017, 7, 7162.

62 J. Feng, S. T. Nguyen, Z. Fan and H. M. Duong, Chem. Eng. J., 2015, 270, 168-175.

63 P. Sharma, B. K. Saikia and M. R. Das, Colloids Surf., A, 2014, 457, 125-133.

64 Y. Chen and D. Zhang, Chem. Eng. J., 2014, 254, 579-585.

65 Y. S. Ho and G. McKay, Process Biochem., 1999, 34, 451-465.

66 H. K. Boparai, M. Joseph and D. M. O'Carroll, J. Hazard. Mater., 2011, 186, 458-465.

67 L. Li, B. Li, H. Sun and J. Zhang, J. Mater. Chem. A, 2017, 5, 14858-14864.

68 Z. Shi, W. Zhang, F. Zhang, X. Liu, D. Wang, J. Jin and L. Jiang, Adv. Mater., 2013, 25, 2422-2427.

69 M. Huang, Y. Si, X. Tang, Z. Zhu, B. Ding, L. Liu, G. Zheng, W. Luo and J. Yu, J. Mater. Chem. A, 2013, 1, 14071-14074.

70 H. Maleki, L. Duraes and A. Portugal, J. Mater. Chem. A, 2015, 3, 1594-1600.

71 X. Wang, H. Zhang and S. C. Jana, J. Mater. Chem. A, 2013, 1, 13989-13999.

72 H. Maleki, S. Montes, N. Hayati-Roodbari, F. Putz and N. Huesing, ACS Appl. Mater. Interfaces, 2018, DOI: 10.1021/acsami.8b05856.

73 C. Rudaz, R. Courson, L. Bonnet, S. Calas-Etienne, H. Sallee and T. Budtova, Biomacromolecules, 2014, 15, 2188-2195.

74 T. Kashiwagi, F. Du, J. F. Douglas, K. I. Winey, R. H. Harris Jr and J. R. Shields, Nat. Mater., 2005, 4, 928-933.

75 T. Kashiwagi, J. W. Gilman, K. M. Butler, R. H. H. Jr, J. R. Shields and A. Asano, Fire Mater., 2000, 24, 277-289.

76 R. C. Hale, M. J. La Guardia, E. P. Harvey, M. O. Gaylor, T. M. Mainor and W. H. Duff, Nature, 2001, 412, 140-141.

77 Z. Li, X. Cheng, L. Gong, Q. Liu and S. Lia, J. Non-Cryst. Solids, 2018, 481, 267-275. 